\title{
Genetic and pharmacological evidence that a retinoic acid cannot be the RXR-activating ligand in mouse epidermis keratinocytes
}

\author{
Cécile Calléja, ${ }^{1,4}$ Nadia Messaddeq, ${ }^{1,4}$ Benoit Chapellier, ${ }^{1}$ Haiyuan Yang, ${ }^{1}$ Wojciech Krezel, ${ }^{1}$ \\ Mei Li, ${ }^{1}$ Daniel Metzger, ${ }^{1}$ Bénédicte Mascrez $^{1}{ }^{1}$ Kiminori Ohta ${ }^{2}{ }^{2}$ Hiroyuki Kagechika, ${ }^{3}$ \\ Yasuyuki Endo, ${ }^{2}$ Manuel Mark, ${ }^{1}$ Norbert B. Ghyselinck, ${ }^{1,4}$ and Pierre Chambon ${ }^{1,4,5}$ \\ ${ }^{1}$ Institut de Génétique et de Biologie Moléculaire et Cellulaire (IGBMC), Institut Clinique de la Souris (ICS), \\ CNRS/INSERM/ULP, Collège de France, 67404 Illkirch Cedex, CU de Strasbourg, France; ${ }^{2}$ Faculty of Pharmaceutical \\ Sciences, Tohoku Pharmaceutical University, Komatsushima, Aoba-ku, Sendai 981-8558, Japan; ${ }^{3}$ School of Biomedical \\ Science, Tokyo Medical and Dental University, Kanda-Surugadai, Chiyoda-ku, Tokyo 101-0062, Japan
}

\begin{abstract}
Using genetic and pharmacological approaches, we demonstrate that both $\operatorname{RAR} \gamma / \operatorname{RXR} \alpha$ heterodimers involved in repression events, as well as $\operatorname{PPAR} \beta(\delta) / \operatorname{RXR} \alpha$ heterodimers involved in activation events, are cell-autonomously required in suprabasal keratinocytes for the generation of lamellar granules (LG), the organelles instrumental to the formation of the skin permeability barrier. In activating PPAR $\beta(\delta) / R X R \alpha$ heterodimers, RXR $\alpha$ is transcriptionally active as its AF-2 activation function is required and can be inhibited by an RXR-selective antagonist. Within repressing $\operatorname{RAR} \gamma / \operatorname{RXR} \alpha$ heterodimers, induction of the transcriptional activity of RXR $\alpha$ is subordinated to the addition of an agonistic ligand for RAR $\gamma$. Thus, the ligand that possibly binds and activates $\operatorname{RXR} \alpha$ heterodimerized with $\operatorname{PPAR} \beta(\delta)$ cannot be a retinoic acid, as it would also bind RAR $\gamma$ and relieve the RAR $\gamma$-mediated repression, thereby yielding abnormal LGs. Our data also demonstrate for the first time that subordination of RXR transcriptional activity to that of its RAR partner plays a crucial role in vivo, because it allows RXRs to act concomitantly, within the same cell, as heterodimerization partners for repression, as well as for activation events in which they are transcriptionally active.
\end{abstract}

[Keywords: Conditional somatic mutagenesis; $\operatorname{RAR} \gamma ; \operatorname{PPAR} \beta(\delta)$; skin permeability barrier; transcriptional subordination; ichthyosis]

Supplemental material is available at http://www.genesdev.org.

Received October 4, 2005; revised version accepted March 13, 2006.

The physiological effects of retinoic acids (RA) are mediated by members of two families of nuclear receptors (NRs), the RAR $\alpha, \operatorname{RAR} \beta$, and RAR $\gamma$ isotypes, and the $\operatorname{RXR} \alpha, \operatorname{RXR} \beta$, and RXR $\gamma$ isotypes. RARs bind both alltrans and 9-cis RA, whereas only the 9-cis RA stereoisomer binds to RXRs. As RAR/RXR heterodimers, these receptors control the transcription of RA-target genes through binding to RA-response elements (RAREs) (Chambon 1996). Transcriptional corepressor complexes associated with histone deacetylase activity are recruited to RAREs by unliganded or retinoid antagonistbound RAR/RXR heterodimers, resulting in chromatin condensation and transcriptional silencing. Upon binding of retinoid agonists, corepressors are released, and

\footnotetext{
${ }^{4}$ These authors contributed equally to this work.

${ }^{5}$ Corresponding author.

E-MAIL chambon@igbmc.u-strasbg.fr; FAX 33-388-653-203.

Article is online at http://www.genesdev.org/cgi/doi/10.1101/gad.368706.
}

recruitment of coactivator complexes exhibiting histone transacetylase activity results in chromatin decondensation and transcription of RA-target genes (Perissi and Rosenfeld 2005). RXRs also heterodimerize with several additional NRs, including peroxisome proliferator activated receptors (PPARs) (Laudet and Gronemeyer 2002). All RAR and RXR genes have been knocked out in the mouse. This genetic approach allowed us to demonstrate that during prenatal development: (1) The RA signal is transduced by RAR/RXR heterodimers. (2) In these heterodimers, functional redundancies may exist both within the RARs and the RXR partners. (3) Within $\operatorname{RXR} \alpha / \operatorname{RAR}(\alpha, \beta$, or $\gamma)$ heterodimers, the ligand-dependent transcriptional activation function (AF-2) of RXR is often required to mediate the pleiotropic effects of RA on morphogenesis and organogenesis (Mark et al. 2006).

The keratinocytes of the epidermis of both humans and mice contain predominantly RAR $\gamma$ and $\operatorname{RXR} \alpha$, while RAR $\alpha$ and RXR $\beta$ are expressed at a much lower level, 
and RAR $\beta$ and RXR $\gamma$ are undetectable (Fisher et al. 1994; Chapellier et al. 2002b). Phenotypic analysis of transgenic mice expressing dominant-negative (dn) RAR $\alpha$ (that lacks the AF-2 transactivating function) either in suprabasal (Imakado et al. 1995; Attar et al. 1997) or in basal (Saitou et al. 1995) epidermis keratinocytes, respectively, led to the proposal that retinoid signaling could be involved in the formation of the epidermal permeability barrier, and in the maturation of the epidermis during development. However, the abnormalities exhibited by these transgenic models may not reflect the actual physiological roles of RA signaling in epidermal homeostasis for at least two reasons: (1) The overexpression of $\operatorname{dnRAR} \alpha$ that heterodimerizes with RXRs may impair other nuclear receptor signaling pathways that require RXRs as heterodimerization partners; and (2) a $\operatorname{dnRAR} \alpha$ tightly associated with a corepressor complex may artifactually interact with DNA sites or proteins not involved in the retinoid signaling pathway (Andersen and Rosenfeld 1995). In this respect, it has been recently reported that dnRARs transgenes expressed in basal keratinocytes may impact on epidermal development through a noncanonical pathway that is independent of receptor-DNA interactions, and most probably involves down-regulation of p63 (Chen and Lohnes 2004).

The selective ablation of RARs and RXRs in mouse epidermis keratinocytes, using cell-type-specific temporally controlled somatic mutagenesis (Metzger et al. 2003), showed that (1) epidermis differentiation in RAR $\gamma$-null mice that also selectively lack RAR $\alpha$ in keratinocytes appears essentially normal at the histological level (Chapellier et al. 2002b), in keeping with the normal histological appearance of the epidermis of adult transgenic mice expressing a dnRXR $\alpha$ (Feng et al. 1997) or a dnRAR $\alpha$ in suprabasal cells (Xiao et al. 1999); and (2) all three RARs are dispensable in adult mouse epidermis for the homeostasic renewal of keratinocytes. This led us to conclude that RA was unlikely to be required for the self-renewal of adult epidermal keratinocytes. That RAR $\gamma$ could nevertheless exert some postnatal function in skin epidermis was suggested by the glossy appearance of RAR $\gamma$-null newborns, which was also observed in newborn pups lacking RXR $\alpha$ in epidermal keratinocytes ( $\mathrm{Li}$ et al. 2001; Chen and Lohnes 2004; our unpublished data).

The present study was initially aimed at elucidating the origin of this glossiness. Unexpectedly, this led to the discovery that unliganded RAR $\gamma$ heterodimerized with $\operatorname{RXR} \alpha$, as well as $\operatorname{PPAR} \beta(\delta)$ heterodimerized with $\operatorname{RXR} \alpha$, are cell-autonomously required in transcriptional repression and activation events, respectively, both of which being instrumental to the formation of small keratinocyte organelles, the lamellar granules (LG), that are involved in the elaboration of the skin permeability barrier.

\section{Results \\ Vesicles without lamellae are formed instead of lamellar granules in RAR $\gamma$-null epidermis}

The normal mouse epidermis is a four-cell-layer stratified epithelium (see Fig. 1E). The innermost basal layer
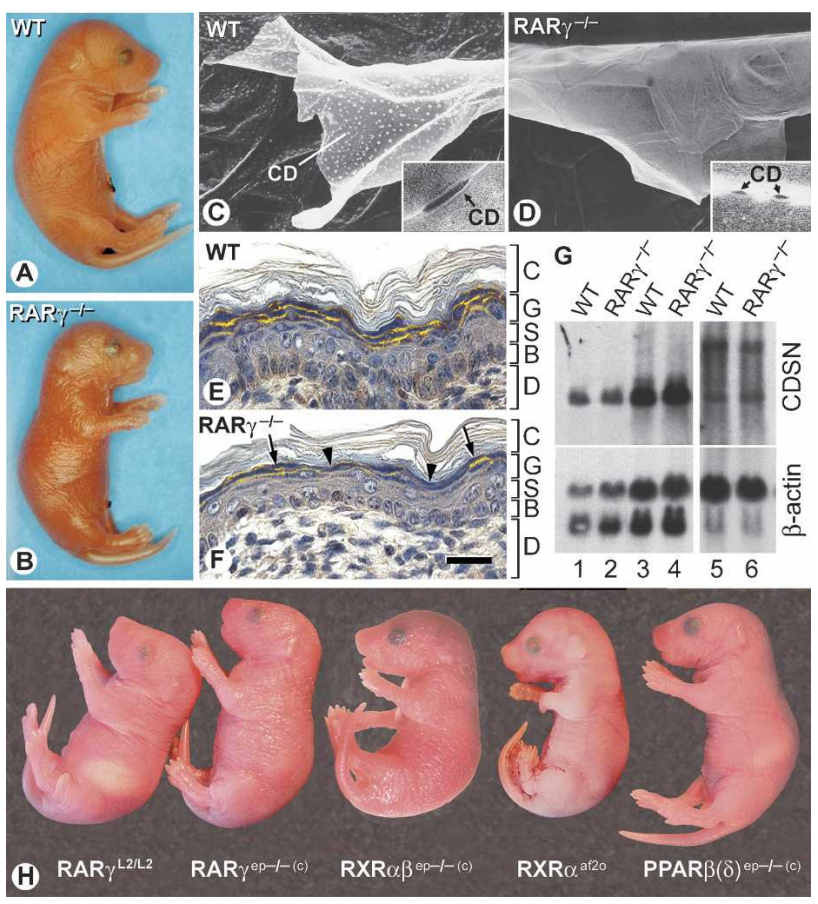

Figure 1. $(A, B)$ Living wild-type $(\mathrm{WT})$ and $\mathrm{RAR} \gamma^{-/-}$newborns. Note the dull and glossy appearance of wild-type and RAR $\gamma^{-/-}$ newborns, respectively. $(C, D)$ Corneodesmosome $(\mathrm{CD})$ alterations in RAR $\gamma^{-1-}$ newborns. STEM views of squames. Insets show TEM views of CD. (E,F) Corneodesmosin (CDSN) distribution revealed by IHC (yellow, false color). In RAR $\gamma^{-/-}$, some granular keratinocytes contain CDSN (arrows), whereas others display less or no CDSN (arrowheads). The section in $E$ is slightly tangential when compared with $F$, resulting in an oval appearance of nuclei. $(G)$ Northern blot of total RNA (25 $\mu \mathrm{g}$ ) from esophagus (lanes 1,2), tongue (lanes 3,4), and back skin (lanes 5,6$)$. Note that two CDSN RNA species are detected in skin. The blot was also hybridized with a $\beta$-actin probe. $(H)$ Newborn external appearance. The skin surface appears dull in controls $\left(\operatorname{RAR} \gamma^{\mathrm{L} 2 / \mathrm{L} 2}\right), \operatorname{RXR} \alpha^{\text {af2o }}$, and $\operatorname{PPAR} \beta(\delta)^{\mathrm{ep}-/(c)}$ mutants, but glossy in RAR $\gamma^{\text {ep-l-(c) }}$ and $\operatorname{RXR} \alpha \beta^{\text {ep- }-(-(c)}$ mutants. (B) Basal layer; (C) cornified layer; (CD) corneodesmosome; (D) dermis; (G) granular layer; (S) spinous layer. Bar in $F$ represents $15 \mu \mathrm{m}$ in $C$ and $D$ and $50 \mu \mathrm{m}$ in $E$ and $F$.

(B) comprises the mitotically active cells that, upon cell cycle withdrawal, lose adhesion to the basement membrane and start their migration toward the skin surface. In the intermediate spinous (S) and granular (G) suprabasal (SB) layers, the cells complete their differentiation program, leading to keratinization. The outermost cornified layer or stratum corneum $(\mathrm{C})$ is composed of highly differentiated, stacked, densely packed, flattened cells (corneocytes) that have lost their nuclei.

RAR $\gamma^{-/-}$newborns were easily identified among their wild-type littermates by the glossy appearance of their skin (Fig. 1A,B). However, their epidermis appeared histologically normal (Fig. 1F; data not shown). Cell proliferation and apoptosis, as assessed by BrdU incorporation and in situ detection of DNA fragmentation, respectively, were unaltered, and expression of specific markers for basal or suprabasal keratinocytes also appeared 
normal (data not shown). To investigate the origin of skin glossiness in RAR $\gamma^{-1-}$ newborns, the surface of exfoliated squames from dorsal skin was examined by scanning transmission electron microscopy (STEM). On wild-type squames, numerous electron-dense plaques, corresponding to desmosome-derived structures called corneodesmosomes (CDs), were observed (Fig. 1C). Using transmission electron microscopy (TEM), CDs appeared as regularly spaced, large plaques (Fig. 1C, inset). In contrast, $\mathrm{RAR} \gamma^{-/-}$exfoliated squames displayed a smooth surface (Fig. 1D), suggesting that CDs were small or lacking. TEM showed that CDs were actually scarce and small in size (Fig. 1D, inset).

Corneodesmosin (CDSN), a protein synthesized into granular keratinocytes, is associated with desmosomes to form CDs (Montézin et al. 1997). In wild-type new- born epidermis, CDSN was easily detected in granular keratinocytes, along the entire skin surface (Fig. 1E). In RAR $\gamma^{-/-}$newborns, CDSN was less abundant and unevenly distributed (Fig. 1F). However, CDSN transcripts were not reduced (Fig. 1G). CDSN being normally packaged into small organelles called lamellar granules (LG) (Ishida-Yamamoto et al. 2004), we examined the epidermis ultrastructure. Numerous cytoplasmic LG were seen in wild-type newborn granular keratinocytes (Fig. 2A). They contained lipids and proteins packaged as stacks of parallel lamellae (Fig. 2A, inset) that were extruded at the apical pole of granular cells (Fig. 2F, bracket), and processed into lipid-rich multilamellar sheets (Madison 2003) to fill most of the space between CDs and along the granular keratinocyte-corneocyte interface (Figs. 2H [inset], 4A [below]). Granular keratino-
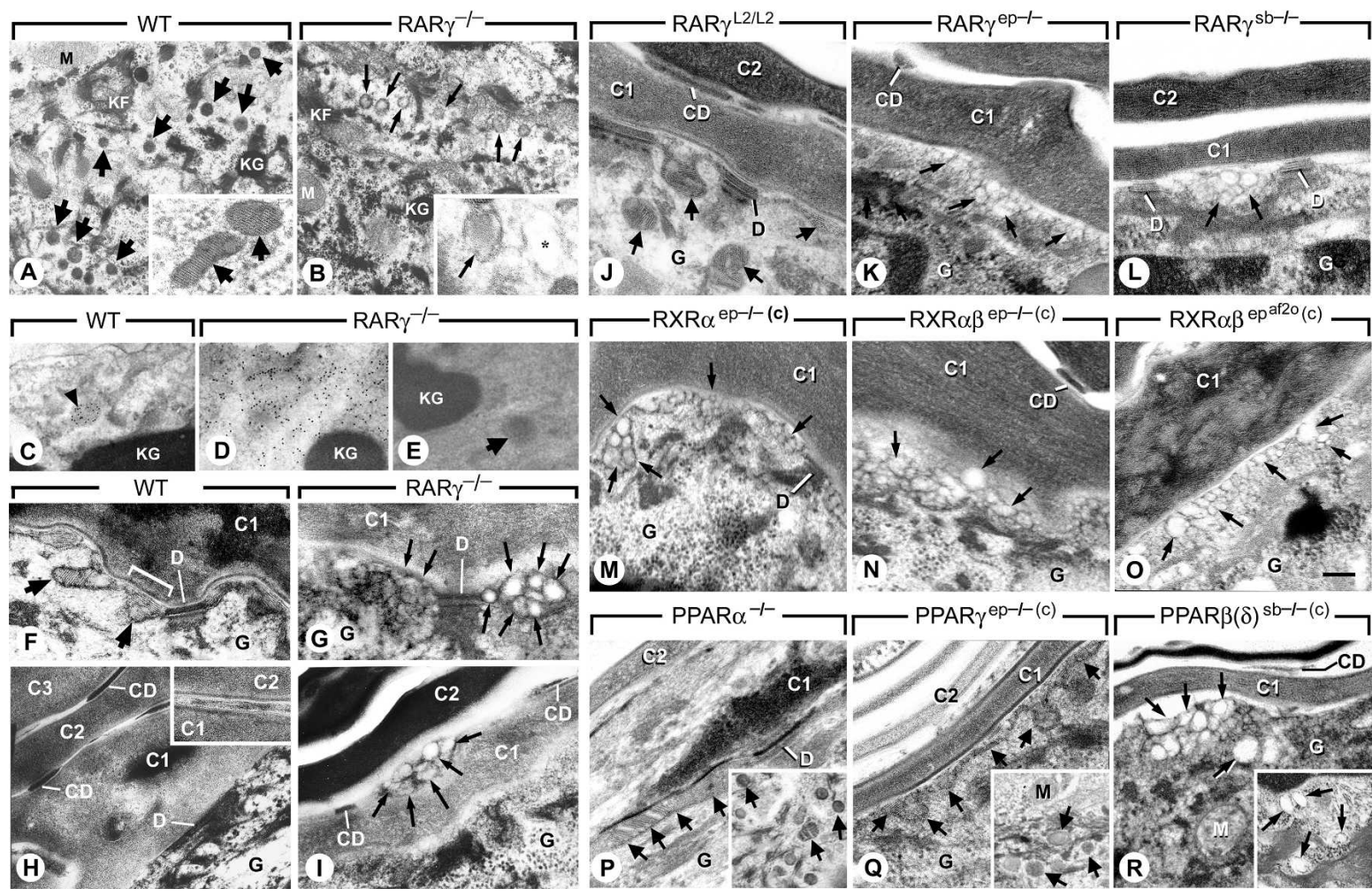

Figure 2. $(A-I)$ Ultrastructure of granular keratinocytes in wild-type $(\mathrm{WT})$ and RAR $\gamma^{-/-}$newborns. $(A, B)$ In wild type, numerous LGs (large arrows) with conspicuous internal lamellar structures (inset) are present, while vesicles that lack (inset, asterisk) or display disorganized lamellae (thin arrows) are observed in $\mathrm{RAR}^{-/-} .(C-E)$ Detection of acid lipase activity at birth. The arrowhead in $C$ points to a LG containing the electron-dense "dotted" lipase reaction product. Incubation without substrate was used as a negative control in $E_{\text {; }}$ the large arrow points to a LG. $(F, G)$ Junction between the outermost granular and the first cornified layer. Large arrows point to wild-type LGs that fuse with the granular keratinocyte membrane to release their lamellar content at the cell surface (bracket). Thin arrows point to vesicle aggregates in $\mathrm{RAR}^{-/-}$. $(H, I)$ Large CDs connect wild-type corneocytes together, and lipid-rich multilamellar sheets fill the space between corneocytes (inset). Smaller CDs and aggregates of vesicles are present between the corneocytes (thin arrows) in RAR $\gamma^{-l-} .(J-R)$ Ultrastructure of granular keratinocytes in adult mice bearing somatic mutations. (J) In Tam-treated control mice, granular keratinocytes contain LGs that release their lipid lamellar content at the cell surface (large arrows), and large CDs connect the corneocytes together. $(K, L)$ In $\mathrm{RAR} \gamma^{\mathrm{ep}-/-}$ and $\mathrm{RAR} \gamma^{\mathrm{sb}-/-}$ mice, vesicles form aggregates at the apical pole of granular keratinocytes (thin arrows), while CDs are small. $(M-R)$ Similar alterations are present in $\operatorname{RXR} \alpha^{\text {ep- }-/(c)}, \operatorname{RXR} \alpha \beta^{\text {ep }-/-(c)}, \operatorname{RXR} \alpha \beta^{\text {ep }}{ }^{\text {af2olc } c}$, and PPAR $\beta(\delta)^{\mathrm{sb}-/-}$ mice, whereas in PPAR $\alpha^{-/-}$and PPAR $\gamma^{\mathrm{ep}-/-(c)}$ mice, granular keratinocytes contain normal LGs releasing their lamellar content at the cell surface (large arrows). Basal and spinous keratinocytes always appeared normal (not shown). C1, C2, and C3 indicate the first, second, and third cornified layers, respectively. (CD) Corneodesmosome; (D) desmosome; (G) granular keratinocyte; (KF) keratin filament bundle; (KG) keratohyalin granule; $(\mathrm{M})$ mitochondria. Bar in $O$ represents $0.5 \mu \mathrm{m}$ in $A$ and $B$; $0.1 \mu \mathrm{m}$ in the insets in $A, B$, and $C-E$; and $0.15 \mu \mathrm{m}$ in $F-R$. 
cytes of RAR $\gamma^{-/-}$newborns contained numerous vesicles devoid of lamellae (Fig. 2B, asterisks in inset) or displaying disorganized lamellae (Fig. 2B), which formed aggregates at the cell apical pole (Fig. 2G) and remained trapped between corneocytes (Fig. 2I). All of these structural abnormalities were consistently observed in the epidermis of both $\mathrm{RAR} \gamma^{-/-}$newborns and adults (data not shown).

To confirm that these vesicles lacking lamellae could correspond to altered LGs, the distribution of acid lipase, known to be packaged into LG (Menon et al. 1986), was analyzed by TEM cytochemistry in newborn epidermis. In wild-type mice, the product of lipase activity (electron-dense dots) was essentially restricted to LGs of granular keratinocytes (Fig. 2C, arrowhead), whereas it was scattered throughout their cytoplasm in $\mathrm{RAR} \gamma^{-/-}$ mutants (Fig. 2D), as if acid lipase packaging into LGs was not properly achieved.

Uneven surface lipid distribution and altered permeability barrier function in $R A R \gamma$-null skin

In addition to proteins, LGs extrude lipids, whose transformation yields the epidermal permeability barrier (Madison 2003). Nile red staining showed that neutral lipids formed a dense, continuous ribbon on top of the cornified layer in wild-type newborn (Fig. 3A) and adult (Fig. 3C) epidermis. In contrast, neutral lipids were unevenly distributed along the cornified layer of the RAR $\gamma^{-1-}$ epidermis (arrowheads), both in newborns (Fig. 3B) and adults (Fig. 3D), suggesting possible alterations of the skin permeability barrier. However, this barrier was not severely altered at birth, as judged from diffusion in the skin of the fluorescent dye Lucifer yellow that was retained in the upper layer of the stratum corneum both in wild-type and RAR $\gamma^{-/-}$littermates (data not shown), as well as from a comparison of weight loss between wild-type and $\operatorname{RAR} \gamma^{-/-}$littermates over a $24-\mathrm{h}$ period (data not shown). In adults, trans-epidermal water loss (TEWL) was increased by $\sim 20 \%$ in $\mathrm{RAR}^{-/-}$mice $\left(6.48 \pm 0.29 \mathrm{~g} / \mathrm{h} \cdot \mathrm{m}^{2}\right.$ in wild type $[n=12]$ vs. $8.12 \pm 0.61$ $\mathrm{g} / \mathrm{h} \cdot \mathrm{m}^{2}$ in $\left.\mathrm{RAR} \gamma^{-/}[n=10] ; p<0.05\right)$, indicating that the permeability barrier function was actually altered.

\section{$R A R \gamma$ and $R X R \alpha$ are required in keratinocytes for lamellar granule formation}

To determine whether the above structural defects reflected a cell-autonomous function of $\operatorname{RAR} \gamma$, somatic mutants in which $\operatorname{RAR} \gamma$ ablation was restricted to epidermal keratinocytes were generated. RAR $\gamma^{\mathrm{L} 2 / \mathrm{L} 2}$ mice bearing floxed RAR $\gamma$ alleles were crossed with either K14-CreER ${ }^{\mathrm{T} 2}$ or CMV-CreER ${ }^{\mathrm{T}}$ transgenic mice that express tamoxifen (Tam)-inducible forms of Cre recombinase in basal or suprabasal keratinocytes, respectively (Metzger et al. 2003). Adults obtained from these crosses were treated with Tam, yielding RAR $\gamma^{\text {ep-/- }}$ or RAR $\gamma^{\text {sb-/- }}$ mice, in which RAR $\gamma$ ablation in all epidermal layers or selectively in the suprabasal layer, respectively, was
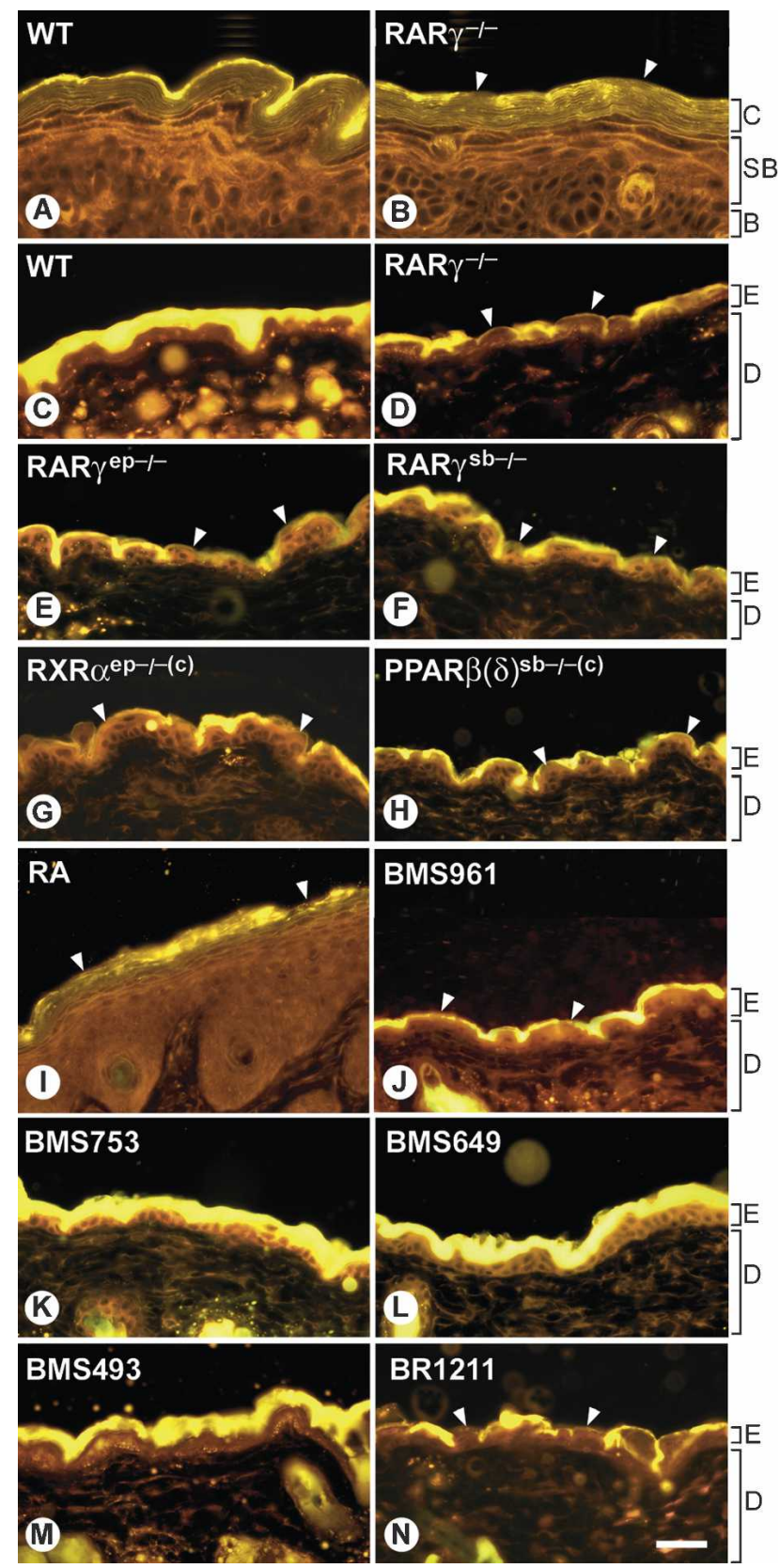

Figure 3. Histochemical detection of lipids in newborn $(A, B)$ and adult $(C-N)$ mice, using Nile red staining. $(A-H)$ On top of the cornified layer, neutral lipids are concentrated as a yellow continuous ribbon in wild-type (WT) epidermis, while their distribution is interrupted (arrowheads) in mutants as indicated. The dermis staining in $C$ is artifactual. $(I-N)$ Surface lipid distribution is interrupted (arrowheads) in wild-type mice topically treated with RA, BMS961, or BR1211, whereas it remains continuous upon topical treatment with BMS753, BMS649, or BMS493. Note in $I$ the typical thickening of the epidermis resulting from RA-induced basal keratinocyte proliferation (Chapellier et al. 2002b). Phospholipid distribution (orange) is not affected. (B) Basal layer; (C) cornified layer; (D) dermis; (E) epidermis; (SB) suprabasal layer. Bar in $N$ represents, $50 \mu \mathrm{m}$ in $A$ and $B$ and $300 \mu \mathrm{m}$ in $C-N$. 
verified by Southern blot analysis and IHC (Metzger et al. 2003). Upon Tam treatment, the epidermis ultrastructure of control littermates $\left(\mathrm{RAR} \gamma^{\mathrm{L} 2 / \mathrm{L} 2}\right)$ was undistinguishable from that of wild-type mice (Fig. 2J). In contrast, both RAR $\gamma^{\mathrm{ep}-/-}$ (Fig. 2K) and RAR $\gamma^{\mathrm{sb}-/-}$ (Fig. 2L) adults displayed an epidermis phenotype identical to that of $\mathrm{RAR} \gamma^{-/-}$mice with regard to (1) alterations of CDs, (2) presence of vesicles forming aggregates at the apical pole of granular keratinocytes, instead of normal LGs (Fig. 2, cf. K,L and G), and (3) uneven neutral lipid distribution at the skin surface (Fig. 3E,F, arrowheads). Thus, ablation of RAR $\gamma$ in suprabasal keratinocytes is sufficient to yield defects in $\mathrm{CD}, \mathrm{LG}$, and surface lipids that were identical to those observed either in RAR $\gamma^{-/-}$ or RAR $\gamma^{\text {ep-l- }}$ mice. Hereafter, we refer to these abnormalities taken collectively as the "LG and related defects." Crossing RAR $\gamma^{\mathrm{L} 2 / \mathrm{L} 2}$ mice with K14-Cre transgenic mice generated $\mathrm{RAR} \gamma^{\mathrm{ep}-/(\mathrm{cc})}$ mice, in which RAR $\gamma$ ablation occurred in keratinocytes during fetal skin development (Li et al. 2001). Like the RAR $\gamma^{\text {ep }-/-}$ adults described above, RAR $\gamma^{\mathrm{ep}-/-(\mathrm{c})}$ newborns exhibited the LG and related defects (data not shown). In addition, the skin surface of RAR $\gamma^{\text {ep-l-(c) }}$ newborns was glossy (Fig. 1H), and at adulthood the TEWL of these mice was increased $\left(6.48 \pm 0.29 \mathrm{~g} / \mathrm{h} \cdot \mathrm{m}^{2}\right.$ in wild type $[n=12]$ vs. $7.51 \pm 0.30$ $\mathrm{g} / \mathrm{h} \cdot \mathrm{m}^{2}$ in $\left.\mathrm{RAR} \gamma^{\mathrm{ep}-/(\mathrm{c})}[n=14] ; p<0.05\right)$. There was apparently no functional redundancy between RAR $\gamma$ and RAR $\alpha$ in keratinocytes, as the same abnormalities were observed in RAR $\gamma^{-1-}$ mice and in mice that, in addition, lacked RAR $\alpha$ selectively in epidermal keratinocytes, while $\mathrm{RAR}^{-/-}$epidermis was normal (Chapellier et al. 2002b; data not shown).

To determine whether $\operatorname{RXR} \alpha$ could be the heterodimerization partner of RAR $\gamma$ in keratinocytes, mice in which $\mathrm{RXR} \alpha$ alleles are floxed $\left(\mathrm{RXR} \alpha^{\mathrm{L} 2 / \mathrm{L} 2}\right)$ were crossed with K14-Cre transgenic mice to generate $\mathrm{RXR} \alpha^{\mathrm{ep}-/-(\mathrm{c})}$ mice, in which $\mathrm{RXR} \alpha$ ablation is restricted to keratinocytes during skin development (Li et al. 2001). As RAR $\gamma^{-/-}$and RAR $\gamma^{\text {ep- }-(-(\mathrm{c})}$ mice, $\operatorname{RXR} \alpha^{\text {ep }-/-(\mathrm{cc})}$ mice exhibited the LG and related defects (Figs. 2M, 3G), and a glossy skin at birth (Li et al. 2001; data not shown). In addition, mice bearing floxed RXR $\alpha$ and RXR $\beta$ alleles $\left(\mathrm{RXR} \alpha \beta^{\mathrm{L} 2 / \mathrm{L} 2}\right.$ mice) were crossed with K14-Cre transgen-

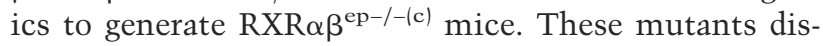
played CD and LG defects (Fig. 2N), as well as skin glossiness (Fig. 1H), identical to those of $\mathrm{RAR} \gamma^{-/-}$, $\mathrm{RAR} \gamma^{\mathrm{ep}-/-(\mathrm{c})}$, and $\mathrm{RXR} \alpha^{\mathrm{ep}-/-(\mathrm{c})}$ mice, while no LG and related defects were seen in RXRß-null mice (data not shown). We concluded from these observations that, for LG formation, there is little or no functional redundancy between $\operatorname{RXR} \alpha$ and $\operatorname{RXR} \beta$, and therefore that heterodimers between RAR $\gamma$ and $\operatorname{RXR} \alpha$ could be instrumental to LG formation in keratinocytes.

\section{Topical treatment with an RAR $\gamma$-selective agonist mimics RAR $\gamma$ ablation, whereas a pan-RAR antagonist has no effect}

The above results prompted us to investigate the effects of topical treatment with RA and selective retinoids on wild-type adult epidermis ultrastructure. Administration of RA ( $40 \mathrm{nmol}$ ) resulted in the disappearance of LGs that are easily recognized in the vehicle-treated control mice (Fig. 4A,D). Instead, and similarly to the LG and related defects, vesicles without lamellae appeared that (1) had the same size and cellular localization as LGs (Fig. 4E), (2) formed aggregates at the apical pole of the outermost granular keratinocytes (Fig. 4B), and (3) were retained between corneocytes (Fig. 4B, asterisk). Accordingly, the size and number of CDs attaching the corneocytes together were reduced (data not shown), the lipid multilamellar sheets between corneocytes did not form at all (Fig. 4, cf. A and B), and neutral lipids were unevenly distributed along the cornified layer (Fig. 3I, arrowheads). In keeping with these results, similar empty vesicles have been previously described in epidermis of RA-fed mice (Elias et al. 1981).

Topical treatment with the RAR $\alpha$-selective agonist BMS753 (40 nmol) or the RXR-selective agonist BMS649 alone $(10 \mathrm{nmol})$ had no effects on LG structure (Fig. $4 \mathrm{C}, \mathrm{F}, \mathrm{H}, \mathrm{K}$ ) and lipid distribution at the skin surface (Fig. $3 \mathrm{~K}, \mathrm{~L})$. In contrast, mice treated with the RAR $\gamma$-selective agonist BMS961 (3 nmol) displayed LG, CD (Fig. 4G,J), and surface lipid defects (Fig. 3J) similar to those described above that were enhanced upon coadministration of $10 \mathrm{nmol}$ of the RXR-selective agonist BMS649 (Fig. $4 \mathrm{I}, \mathrm{L}$ ). It is worth noting that the LG and related defects are independent of keratinocyte proliferation, as they were observed using a dose of BMS961 $(3 \mathrm{nmol})$ too low to induce epidermal hyperplasia (Supplementary Fig. 1C). These synergistic effects between BMS961 and BMS649 indicate that the RA-induced alterations in keratinocytes resulted from activation of RXR/RAR $\gamma$ heterodimers, in which transactivation by RXR was subordinated to binding of an agonistic ligand to RAR $\gamma$.

Importantly, treatment with the pan-RAR antagonist BMS493 (40 nmol) did not alter structure and extrusion of LGs at the apical pole of the outermost granular keratinocytes (Fig. 4M,P), nor was neutral lipid distribution irregular at the epidermis surface (Fig. 3M). The effectiveness of the BMS493 treatment was checked by its ability to counteract the BMS961-induced expression of the RA-controlled Cyp26a1 and Crabp2 genes (Supplementary Fig. 1G). Note that, on its own, treatment with acetone (the vehicle for retinoids) had no effect on LG structure (Fig. 4A,D) and lipid distribution at the skin surface (data not shown), while none of the topical treatments altered RAR $\gamma$ expression (Supplementary Fig. 2B). Altogether, the above data show that blocking RA signaling through treatment with the pan-RAR antagonist BMS493 did not alter the structure of LGs, whereas activating RA signaling, through treatment with RA or with a RAR $\gamma$-selective agonist, produced LG alterations identical to those observed upon ablation of RAR $\gamma$ and RXR $\alpha$ in keratinocytes. As unliganded RAR/RXR heterodimers can repress gene transcription through interaction with corepressors (Perissi and Rosenfeld 2005), we concluded that the LG defects exhibited by RAR $\gamma$ and RXR $\alpha$ loss-of-function mutants most likely reflected the artifactual expression of one or several genes, whose ex- 
Calléja et al.

Figure 4. Epidermis ultrastructure in adult mice topically treated with retinoids. $(A-R)$ TEM views from mice treated as indicated using acetone (vehicle control), RA, BMS753, BMS961, BMS649 alone or in combination with BMS961, BMS493, and BR1211 alone or in combination with BMS649. In control, BMS753-, BMS649-, and BMS493-treated mice, normal LGs releasing their lipid content at granular keratinocyte apical pole (large arrows) to form multilamellar sheets between corneocytes (brackets) are observed. In RA-, BMS961-, and BR1211-topically treated mice, vesicles (thin arrows) form aggregates at the granular keratinocyte apical pole, and persist between corneocytes (asterisks). Coadministration of BMS649 and BMS961 worsens the defects. Coadministration of BMS649 mostly prevents the appearance of the BR1211-induced defects, although few aggregates can be observed between corneocytes (asterisk in O). $\mathrm{C} 1$ and $\mathrm{C} 2$ indicate the first and second cornified layers, respectively. (D) Desmosome; $(G)$ granular keratinocyte. Bar in $R$ represents $0.1 \mu \mathrm{m}$ in $A-C, G-I$, and $M-O$, and $0.5 \mu \mathrm{m}$ in $D-F$, $J-L$ and $P-R$.

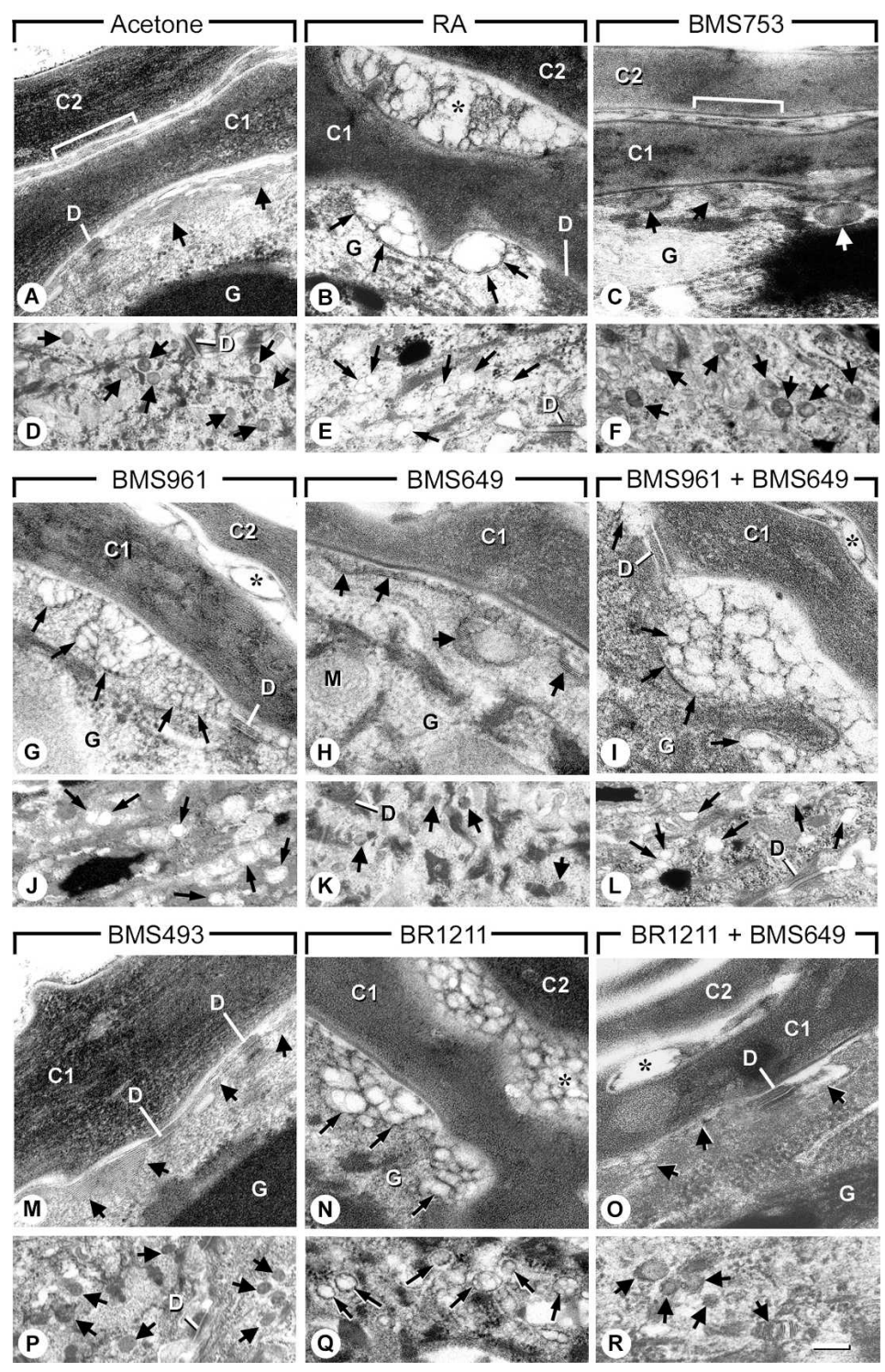

pression was normally repressed by unliganded RAR $\gamma /$ $\mathrm{RXR} \alpha$ heterodimers.

Transcriptional activation mediated by PPAR $\beta$ is also required for the formation of lamellar granules

According to the above repression scenario, impairment of the AF-2 ligand-dependent transcriptional activation functions of RXR $\alpha$ and RXR $\beta$ should not affect LG structure. Unexpectedly, the epidermis of RXR $\alpha^{\text {af2o }}$ (Mascrez et al. 1998) newborns and of RXR $\alpha \beta^{\text {ep }^{\text {ar2o(c) }}}$ adult mice expressing, respectively, RXR $\alpha$ or RXR $\alpha$ and RXR $\beta$ that are deleted for their AF-2 core (helix 12) actually displayed the LG and related defects (Fig. 2O). In keeping with these observations, topical application of $10 \mathrm{nmol}$ of the selective pan-RXR antagonist BR1211 (Supplementary Fig. 1; Ohta et al. 2004) on wild-type adult skin also resulted in the appearance of the LG and related defects (Figs. 4N,Q, 3N). Importantly, these BR1211-induced LG defects were mostly prevented upon coadministration of $200 \mathrm{nmol}$ of the RXR-selective agonist BMS649 (Fig. $4 \mathrm{O}, \mathrm{R})$. Altogether, these observations suggested that the generation of LGs requires, in addition to an unliganded RAR $\gamma /$ RXR-mediated repression, either an RXR homodimer-mediated activation, or a NR/RXR-mediated activation in which RXR AF-2 would synergistically act with a NR heterodimerization partner distinct from RAR $\gamma$.

That PPARs are involved in lipid metabolism and expressed in keratinocytes prompted us to examined the epidermis of mice bearing PPAR-null mutations. We generated PPAR $\gamma^{\mathrm{ep}-/-(\mathrm{c})}$ and $\operatorname{PPAR} \beta(\delta)^{\mathrm{ep}-/-(\mathrm{c})}$ mice, selectively lacking either PPAR $\gamma$ or $\operatorname{PPAR} \beta(\delta)$ in keratinocytes, through crossing mice bearing floxed PPAR $\gamma$ or $\operatorname{PPAR} \beta(\delta)$ alleles with K14-Cre transgenics, and also used $\mathrm{PPAR}^{-/-}$mice (Lee et al. 1995). The PPAR $\alpha^{-/-}$(Fig. 2P) and PPAR $\gamma^{\text {ep-/-(c) }}$ (Fig. 2Q) epidermis ultrastructure and surface lipid distribution were normal. In contrast, 
and similarly to RXR loss-of-function mutants, $\operatorname{PPAR} \beta(\delta)^{\text {ep- }-/(\mathrm{cc})}$ mutants displayed LG and related defects (data not shown), as well as uneven CDSN distribution along the granular layer (Supplementary Fig. 3). To determine whether these defects reflected the requirement of $\operatorname{PPAR} \beta(\delta)$ in basal or in suprabasal keratinocytes, $\operatorname{PPAR} \beta(\delta)^{\mathrm{L} 2 / \mathrm{L} 2}$ mice were crossed with K10CreER ${ }^{\mathrm{T} 2}$ transgenics that express the Tam-inducible Cre in suprabasal keratinocytes. Adults obtained from these crosses were treated with Tam, yielding $\operatorname{PPAR} \beta(\delta)^{\mathrm{sb}-/-}$ mice. Importantly, ablation of $\operatorname{PPAR} \beta(\delta)$ in suprabasal keratinocytes of these mice resulted in the LG and related defects (Figs. 2R, 3H). These results strongly suggested that, in addition to RXR/RAR $\gamma$ heterodimers, heterodimers between RXR $\alpha$ and PPAR $\beta$ were also cell-autonomously required in suprabasal keratinocytes for the generation of LG. Note that none of the retinoid topical treatments that were used altered $\operatorname{PPAR} \beta(\delta)$ expression (Supplementary Fig. 2B).

\section{Ablation of PPAR $\beta(\delta)$ most probably alters lamellar granule formation through decreasing cholesterol synthesis}

Impairment of cholesterol synthesis has been shown to induce LG defects (Menon et al. 1992). However, the transcript levels of Hmgcs1 and Hmgcr (coding for 3-hydroxy-3-methylglutaryl coenzyme A [HMG-CoA] synthase 1 and HMG-CoA reductase, respectively) were not altered in $\operatorname{RAR} \gamma^{\text {ep- }-/-}$ and $\operatorname{PPAR} \beta(\delta)^{\text {ep- }-(-(\mathrm{c})}$ newborn epidermis (Supplementary Fig. 2C). In contrast, the level of Hmgcs2 transcript (coding for HMG-CoA synthase 2) was strongly reduced in $\operatorname{PPAR} \beta(\delta)^{\text {ep- }-/(\mathrm{cc})}$ and

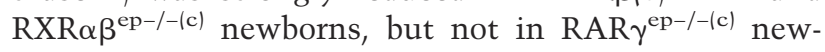
borns (Fig. 5A). Accordingly, TLC analysis of lipids extracted from the skin surface indicated a marked decrease in cholesterol in $\operatorname{PPAR} \beta(\delta)^{\mathrm{ep}-/(\mathrm{cc})}$ and $\operatorname{RXR} \alpha \beta^{\mathrm{ep}-/(\mathrm{cc})}$ newborns (Fig. 5B), but not in RAR $\gamma^{\text {ep- }-(-(\mathrm{c})}$ newborns (data not shown). Thus, even though the LG and related defects generated by either $\operatorname{RAR} \gamma$ and $\operatorname{PPAR} \beta(\delta)$ ablation appear similar, Hmgcs2 expression is not affected by RAR $\gamma$ ablation, indicating that the target genes of RAR $\gamma /$ $\operatorname{RXR} \alpha$ and $\operatorname{PPAR} \beta(\delta) / \mathrm{RXR}$ heterodimers could be different, which is in keeping with the observation that the skin of $\mathrm{RAR} \gamma^{\mathrm{ep}-/-(\mathrm{c})}$ newborns is shiny, in contrast to that of $\operatorname{PPAR} \beta(\delta)^{\text {ep-l-(c) }}$ mutants (Fig. $\left.1 \mathrm{H}\right)$. Even though none of the other possible target genes that we analyzed exhibited an altered expression in $\mathrm{RAR} \gamma^{\mathrm{ep}-/-(\mathrm{c})}$ or $\operatorname{PPAR} \beta(\delta)^{\text {ep }-/-(\mathrm{c})}$ newborn epidermis (Supplementary Fig. $2 C)$, our data clearly indicate that $\operatorname{PPAR} \beta(\delta) / \operatorname{RXR} \alpha$ heterodimers could be instrumental to LG formation through controlling cholesterol synthesis. In this respect, we found that a topical administration of cholesterol to $\operatorname{PPAR} \beta(\delta)^{\text {ep- }-(-(\mathrm{c})}$ adults cured the LG and related defects (Fig. 5C,D).

It is commonly thought that PPAR/RXR heterodimers are permissive heterodimers in which RXR can activate transcription of target genes upon binding of its cognate ligand, even when PPAR is unliganded (Gronemeyer et al. 2004; Chambon 2005). Accordingly, expression of Hmgcs2 was approximately threefold increased in the skin of wild-type adult mice topically treated with the pan-RXR agonist BMS649, whereas it was markedly decreased upon topical treatment with the pan-RXR-selective antagonist BR1211 (Fig. 5E), indicating that Hmgcs2 expression was enhanced by $\operatorname{PPAR} \beta(\delta) / R X R$ heterodimers in which the RXR partner was actually transcriptionally active. In keeping with this conclusion, expression of Hmgcs2 was markedly reduced in $\operatorname{RXR} \alpha \beta^{\text {ep }^{\text {ar2o }}}$ adult mutant mice (Fig. 5F), which selectively express in their keratinocytes RXR $\alpha$ and RXR $\beta$ lacking AF-2. Moreover, expression of Hmgcs2 was approximately threefold increased in the skin of wild-type adult mice treated with the PPAR $\beta(\delta)$-selective agonist L165041 (Fig. 5E), indicating that the PPAR partner can also be transcriptionally active. To investigate their possible synergistic action, we tested whether topical application of the $\operatorname{PPAR} \beta(\delta)$ agonist L165041 could rescue the LG and related defects observed in mice expressing $\operatorname{RXR} \alpha$ and RXR $\beta$ lacking their AF-2. Like their RXR $\alpha \beta^{\text {ep }^{\text {ar2o(c) }}}$ newborn counterparts (Fig. 2O), RXR $\alpha \beta^{\text {ep }^{\text {at2o }}}$ adult mutants displayed the LG and related defects (Fig. 6C, G, K). Interestingly, upon treatment with the L165041 agonist, the

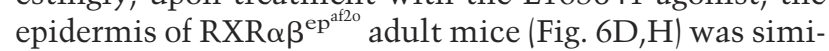
lar to that of control mice (Fig. 6A,B,E,F), and Nile red staining showed that, as in controls (Fig. 6I,J), neutral lipids formed a continuous ribbon on top of the cornified layer in L165041-treated $\mathrm{RXR} \alpha \beta^{\mathrm{ep}^{\mathrm{a} 220}}$ adult epidermis (Fig. 6L). In keeping with these observations, expression of Hmgcs2 was enhanced in the skin of $\operatorname{RXR} \alpha \beta^{\mathrm{ep}^{\text {ar2 }}}$ adults treated with L164051 (Fig. 5F). Therefore, topical administration of L165041 increases Hmgcs2 expression, and restores LG structure and extrusion in keratinocytes of mice expressing RXR $\alpha$ and RXR $\beta$ that are both lacking their AF-2.

\section{Ablation of RXR $\alpha$ AF-2 abrogates the transcriptional activity of $R X R \alpha$, but does not silence the PPAR $(\delta)$ partner}

Our above data strongly suggest that, within $\operatorname{RXR} \alpha /$ $\operatorname{PPAR} \beta(\delta)$ heterodimers, the ablation of RXR $\alpha$ AF- 2 does not silence the transcriptional activity of the PPAR $\beta(\delta)$ partner. Alternatively, as deleting the AF-2 helix 12 could possibly convert RXR into a transcriptional repressor due to increased affinity for corepressors (Zhang et al. 1999), the ablation of RXR $\alpha$ AF-2 may have decreased the activity of the RXR $\alpha \Delta \mathrm{AF}-2 / \operatorname{PPAR} \beta(\delta)$ heterodimer through silencing of $\operatorname{PPAR} \beta(\delta)$. To investigate this possibility, we first performed electrophoretic mobility shift assays (EMSA) using the Hmgcs2 PPAR-response element (PPRE). Deleting helix 12 of RXR $\alpha$ did not impair the heterodimer binding to the PPRE (Fig. 5G). We then analyzed the activity of $\operatorname{RXR} \alpha / \operatorname{PPAR} \beta(\delta)$ and $\mathrm{RXR} \alpha \Delta \mathrm{AF}$ $2 / \operatorname{PPAR} \beta(\delta)$ heterodimers in transiently transfected HepG2 cells, using a Hmgcs2 PPRE-containing reporter (Fig. 5H). Compared with basal conditions (Fig. 5H, lane $3), \operatorname{RXR} \alpha / \operatorname{PPAR} \beta(\delta)$-transfected cells treated either with the RXR-selective ligand BMS649 (Fig. 5H, lane 4) or with increasing concentrations of L165041 (Fig. 5H, lanes $7,11,15$ ) exhibited a significant increase in expres- 
Figure 5. $(A-F)$ Alteration of cholesterol metabolism upon $\operatorname{PPAR} \beta(\delta)$ or $\operatorname{RXR} \alpha$ (and $\beta$ ) ablations in keratinocytes. (A) Real-time quantitative RT-PCR analysis for Hmgcs2 transcripts in total RNA from wild-type (WT), $\operatorname{RAR} \gamma^{\text {ep-l-(c) }}, \operatorname{RXR} \alpha \beta^{\text {ep- }-(c)}$, and $\operatorname{PPAR} \beta(\delta)^{\text {ep- }-(c)}$ newborn epidermis. Values (arbitrary units) correspond to the mean amount \pm SEM of RNA transcripts detected in the epidermis of each genotype $(n=4)$, relative to the amount of $\beta$-actin transcripts (unchanged upon mutation). (B) TLC analysis of lipids from the surface of newborns with genotypes as indicated. (Lanes 1,10) Lipid standards. (C) Cholesterol; (CE) cholesteryl ester (stearate); (Cer) ceramides; (FA) fatty acids. (C,D) TEM views from $\operatorname{PPAR} \beta(\delta)^{\text {ep }-I-(c)}$ epidermis topically treated with cholesterol. (C) In ethanol (vehicle)-treated mutants, vesicles aggregate at the granular keratinocyte apical pole and persist between corneocytes (asterisk). (D) In cholesterol-treated mutants, LGs release their lipid content at the granular keratinocytes apical pole to form multilamellar sheets (brackets). Aggregates of vesicles present between corneocytes (asterisk) arise from the $\operatorname{PPAR} \beta(\delta)$-null keratinocytes that differentiated into corneocytes before the onset of cholesterol administration. $\mathrm{C} 1$ and $\mathrm{C} 2$ indicate the first and second cornified layers, respectively. (CD) Corneodesmosome; (D) desmosome; (G) granular keratinocyte. Bar in $D$ represents $0.1 \mu \mathrm{m}$. (E) Real-time quantitative RT-PCR analysis for $\mathrm{Hmgcs} 2$ transcripts in total RNA from back skin of wild-type adult mice topically treated with acetone vehicle, BMS649, BR1211, or L165041. Values (arbitrary units) correspond to the mean amount \pm SEM of RNA transcripts detected in each series ( $n=3)$, relative to the amount of glyceraldehyde-3-phosphate dehydrogenase transcripts (unchanged upon topical treatment). (F) Real-time quantitative RT-PCR analysis for Hmgcs2 transcripts in total RNA from the back skin of wild-type and RXR $\alpha \beta^{\mathrm{ep}^{\mathrm{a} 200}}$ mice treated with ethanol vehicle or L165041. Values (arbitrary units) correspond to the mean amount \pm SEM of RNA transcripts detected in the skin of each genotype $(n=3)$, relative to the amount of 36B4 transcripts (unchanged upon mutation). (A,E,F) Asterisks indicate a significant difference from the wild-type values $(p<0.05)$. $(G, H)$ Effects of AF-2 deletion on binding property and transcriptional activity of RXR $\alpha$ in heterodimer with $\operatorname{PPAR} \beta(\delta)$. (G) EMSA showing that both $\operatorname{RXR} \alpha / \operatorname{PPAR} \beta(\delta)$ (lane 4) and $\operatorname{RXR} \alpha \Delta \operatorname{AF}-2 / \operatorname{PPAR} \beta(\delta)$ (lane 12) heterodimers $(\mathrm{H})$ equally bind to the Hmgcs2 PPRE (p). The complexes formed were supershifted by addition of antibodies against RXR $\alpha$ (closed arrowhead, lanes 5,13) or PPAR $\beta(\delta)$ (open arrowhead, lanes 6,14). EMSA competitions were performed with a 1000-fold excess of unlabeled PPRE (lanes 7,15) or mutated PPRE (m, lanes 8,16). The left inset shows SDS-PAGE analysis of in vitro translated proteins, indicating that $\operatorname{RXR} \alpha($ lane $b), \operatorname{RXR} \alpha \Delta \operatorname{AF}-2$ (lane $c$ ), and $\operatorname{PPAR} \beta(\delta)($ lane $d$ ) were produced with similar efficiencies. Lane $a$ contains the same amount of lysate translated without receptor cDNA template. (H) HepG2 cell transfections with the Hmgcs2 PPRE-tk-Cat reporter, and $\mathrm{RXR} \alpha-$, RXR $\alpha \Delta \mathrm{AF}-2-$, and $\operatorname{PPAR} \beta(\delta)$-expressing vectors, as indicated. The ligand for $\mathrm{RXR} \alpha(\mathrm{BMS649})$ was added at 5.10 ${ }^{-7}$ $\mathrm{M}$, as indicated. The ligand for PPAR $\beta(\delta)$ (L165041) was added at increasing concentrations: $10^{-8} \mathrm{M}$ (gray bars), $10^{-7} \mathrm{M}($ dark-gray bar), and $10^{-6} \mathrm{M}$ (black bars). (White bars) No L165041 added. Four independent experiments were performed with triplicate transfections for each condition. Bars show the mean CAT activity \pm SEM relative to $\beta$-galactosidase activity. $\left({ }^{\star}, \S, \#\right)$ Indicate a significant difference versus lane $3(p<0.01)$, lane $4(p<0.001)$, and lane $5(p<0.01)$, respectively. There is no significant change between lanes 3, 5, and 6; lanes 7, 9, and 10; lanes 11, 13, and 14; and lanes 15, 17, and 18 .

sion of the reporter. When both compounds were added together (Fig. $5 \mathrm{H}$, lanes $8,12,16$ ), there was a synergistic increase in reporter expression at all three L165041 concentrations. Importantly, in $\operatorname{RXR} \alpha \Delta \mathrm{AF}-2 / \operatorname{PPAR} \beta(\delta)-$ transfected cells, the reporter expression was still significantly increased upon addition of L165041 (Fig. 5H, cf lanes 9,13,17 and 5), but no synergism was observed upon addition of BMS649 (Fig. 5H, lanes 10,14,18). It appears therefore that both ligand-activated $\mathrm{RXR} \alpha$ and $\operatorname{PPAR} \beta(\delta)$ can effectively contribute to the increased transcription of responsive genes, and that deleting $\mathrm{RXR} \alpha$ AF- 2 selectively abrogates the RXR $\alpha$-dependent activity. Therefore, assuming that deletion of AF-2 helix 12 is equivalent to the absence of an agonistic ligand (Mascrez et al. 1998), a liganded RXR $\alpha$ appears to be required to maintain Hmgcs2 expression to a level compatible with efficient LG formation.

\section{Discussion}

Late during granular keratinocyte differentiation, ovoid organelles named lamellar granules (LGs) are formed from the tubular branched portion of the Golgi apparatus. LGs contain lipids (e.g., phospholipids and cholesterol), hydrolytic enzymes (e.g., lipases, proteases), and other proteins (e.g., corneodesmosin, CDSN), which are organized as lamellae. At the apical pole of the outermost granular keratinocytes, LGs release their content, which is then assembled into multilamellar lipid sheets surrounding the corneocytes, and also contributes to the formation of corneodesmosomes and of a continuous ribbon of neutral lipids evenly distributed on top of the cornified layer, thereby participating in generation of the skin permeability barrier (Madison 2003).

Our present data reveal that the keratinocyte-selective 


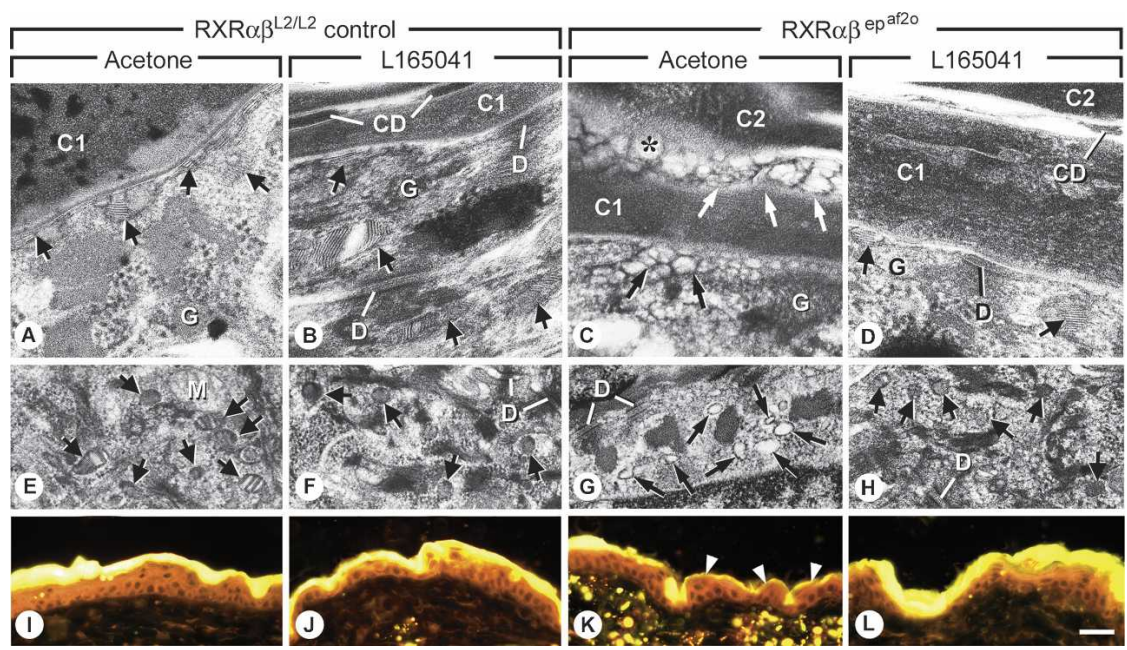

Figure 6. Effects of $\operatorname{PPAR} \beta(\delta)$ activation on epidermis ultrastructure and surface lipid distribution in adult mice with genotypes as indicated. TEM views $(A-H)$ and histochemical detection of lipids using Nile red staining $(I-L)$ in control mice $\left(\mathrm{RXR} \alpha \beta^{\mathrm{L} 2 / \mathrm{L} 2}\right)$ and in mutants expressing $\operatorname{RXR} \alpha$ and $\operatorname{RXR} \beta$ lacking their AF-2 $\left(\operatorname{RXR} \alpha \beta^{\mathrm{ep}^{\mathrm{af20}}}\right)$, topically treated with acetone vehicle or with the PPAR $\beta(\delta)$-selective agonist L165041. $(A, B, E, F, I, J)$ In controls, normal LGs (large arrows) release their content at the granular keratinocyte apical pole, and lipid distribution is even. $(C, G, K)$ In $\operatorname{RXR} \alpha \beta^{\text {ep }}{ }^{\text {af2o }}$ mice treated with acetone, vesicles (thin arrows) form aggregates that persist between corneocytes, and lipid distribution is interrupted (arrowheads). $(D, H, L)$ Topical administration of L165041 to RXR $\alpha \beta^{\text {ep }^{\text {at2o }}}$ mice cures LG and surface lipid defects. C1 and C2 indicate the first and second cornified layers, respectively. (CD) Corneodesmosomes; (D) desmosome; (G) granular keratinocyte; (M) mitochondria. Bar in $L$ represents $0.1 \mu \mathrm{m}$ in $A-D, 0.5 \mu \mathrm{m}$ in $E-H$, and $160 \mu \mathrm{m}$ in $I-L$.

genetic ablation of either $\operatorname{RAR} \gamma, \operatorname{PPAR} \beta(\delta)$, or $\operatorname{RXR} \alpha$ in the mouse impairs the formation of these multilamellar lipid sheets and of the corneodesmosomes, and alters the even distribution of neutral lipids on top of the cornified layer. That, concomitantly, the mutant granular keratinocytes contain vesicles whose size and localization are similar to those of LGs and that are unable to fuse to the membrane of the outermost granular keratinocytes leaves little doubt that the primary defect(s) in these keratinocytes lie(s) in LG biogenesis. This conclusion is further supported by the observation that (1) the acid lipase that is normally associated with LGs is found scattered throughout the cytoplasm of RAR $\gamma$-null granular keratinocytes, and (2) CDSN, a protein normally packaged in LGs, is not regularly detected along the suprabasal layers of the mutant mice. Thus, the biogenesis of LGs in granular keratinocytes offers an interesting integrated model system in vivo to unveil the molecular mechanisms that allow two NR signaling pathways, those of $\operatorname{RAR} \gamma$ and $\operatorname{PPAR} \beta(\delta)$, to keep their identity, while sharing the same $\mathrm{RXR} \alpha$ heterodimerization partner. Whether and how RAR $\gamma / \operatorname{RXR} \alpha$ and $\operatorname{PPAR} \beta(\delta) / \operatorname{RXR} \alpha$ heterodimers control gene expression, how actively $\operatorname{RXR} \alpha$ participates in this control within these heterodimers, whether or not there is any evidence that $\operatorname{RXR} \alpha$ could be liganded and what the nature of the ligand possibly could be are some of the questions that we raised.

Repressing heterodimers between unliganded $R A R \gamma$ and $R X R \alpha$ are cell-autonomously required for the generation of LGs in suprabasal keratinocytes

The finding of identical LG and stratum corneum defects in RAR $\gamma$-null and suprabasal keratinocyte-selective $\mathrm{RAR} \gamma^{\text {sb-/- }}$ mutants demonstrates that RAR $\gamma$ acts cellautonomously in suprabasal keratinocytes. This action is a transcriptional repression, as a topical treatment with a pan-RAR antagonist (BMS493) had no effect on epidermis structure, whereas a treatment with all-trans RA or with a RAR $\gamma$-selective agonist (BMS961), but not with a RAR $\alpha$-selective agonist (BMS763), generates LG defects identical to those resulting from RAR $\gamma$ ablation. Furthermore, these defects were worsened by cotreatment with the RAR $\gamma$-selective ligand and a pan-RXR agonist (BMS649), which on its own had no effect on LG structure. This synergism indicates that the RAR $\gamma$ agonist-induced LG defects result from activation of RAR $\gamma$ / $\mathrm{RXR} \alpha$ heterodimers, previously shown to operate in suprabasal keratinocytes (Chapellier et al. 2002b), and in which transactivation by RXR is subordinated to the binding of an agonist ligand to $\operatorname{RAR} \gamma$.

That heterodimers between unliganded RAR $\gamma$ and RXR mediate repression events in epidermal keratinocytes is in keeping with the expression of the SMRT (NcoR2) and NCoR (NcoR1) corepressors in mouse epidermal keratinocytes, and with the effect of a topical treatment with the histone deacetylase inhibitor trichostatin A (Yoshida et al. 1990) that results in epidermis defects very similar, if not identical, to those displayed by RAR $\gamma$ loss-of-function mutants (Supplementary Fig. 4). It is also in keeping with the apparent lack of RA in epidermis (Randolph and Siegenthaler 1999; Saurat et al. 1999) and with the lack of LG abnormalities in vitamin A-deficient mice (Supplementary Fig. 5). Thus, we conclude that $\operatorname{RAR} \gamma / \operatorname{RXR} \alpha$-mediated repression events are cell-autonomously mandatory for LG biogenesis in suprabasal keratinocytes (Fig. 7A). When this repression is relieved, which can be achieved with doses of retinoids lower than those required for triggering the $\operatorname{RAR} \gamma /$ RXR $\alpha$-mediated proliferation of basal keratinocytes (Supplementary Fig. 1; Chapellier et al. 2002b), the production of LGs is impaired due to the artifactual derepression of target gene(s), whose identity and function remain to be determined. 


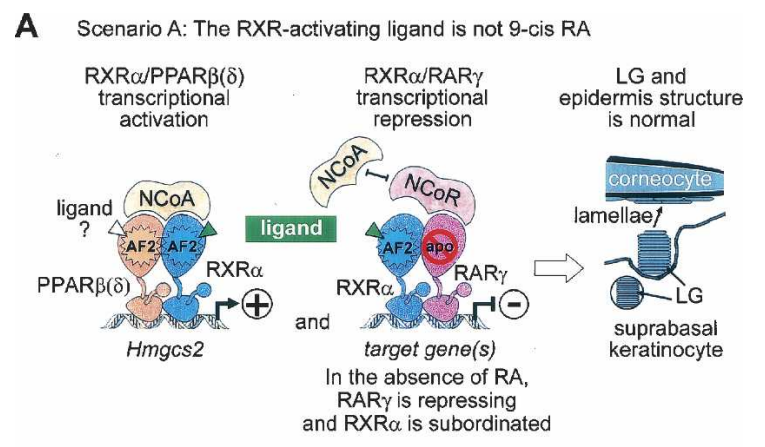

B Scenario B: The RXR-activating ligand is 9-cis RA

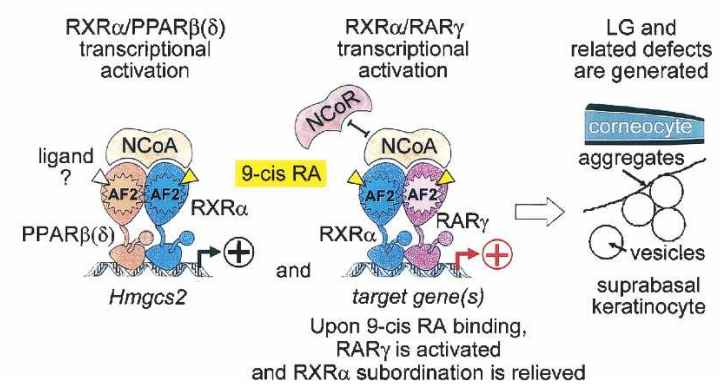

Figure 7. The concomitant occurrence of RAR/RXR-mediated repression and RXR/PPAR $\beta(\delta)$-mediated activation events observed in mouse epidermis suprabasal keratinocytes refutes the possibility that the ligand activating RXR AF-2 could be 9-cis RA. (A) Scenario A: The RXR-activating ligand is not 9-cis RA. Within activating $\operatorname{PPAR} \beta(\delta) / \mathrm{RXR} \alpha$ heterodimers, the AF- 2 of $\mathrm{RXR} \alpha$ is required to activate gene expression, notably that of Hmgcs2. Thus, RXR $\alpha$ most likely binds an agonistic ligand, and $\operatorname{PPAR} \beta(\delta) / R X R \alpha$ heterodimers interact with coactivators (NcoAs/SRCs) (shown in the left panel). On the other hand, within repressing RAR $\gamma / \operatorname{RXR} \alpha$ heterodimers, $\operatorname{RXR} \alpha$ cannot be transcriptionally active, due to subordination of its transcriptional activity to that of its repressing RAR $\gamma$ partner, which has to be in its unliganded apo-form in order to bind corepressors (NcoR/SMRT) that block the transcriptional activity of RXR $\alpha$ (shown in the middle panel). It follows that there should not be any retinoic acids in suprabasal keratinocytes, and therefore that the RXR-activating ligand cannot be 9-cis RA. Under these conditions, lamellar granule (LG) formation and epidermis ultrastructure are normal (shown in the right panel). (B) Scenario $\mathrm{B}$ : The RXR-activating ligand is 9-cis RA. In this case, $\mathrm{RXR} \alpha$ binds 9-cis RA and $\operatorname{PPAR} \beta(\delta) / \mathrm{RXR} \alpha$ heterodimers interact with coactivators (NcoAs/SRCs) (shown in the left panel). However, 9-cis RA also binds to RAR $\gamma$, thus relieving $\mathrm{RXR} \alpha$ subordination and activating RAR $\gamma / \operatorname{RXR} \alpha$ heterodimers, which no longer repress gene expression (shown in the middle panel). Under these conditions, LG biogenesis is impaired (shown in the right panel). As this is not actually the case, the possibility that 9-cis RA could be the ligand activating RXR AF-2 is ruled out.

Activating heterodimers between $P P A R \beta(\delta)$ and $a$ transcriptionally active $R X R \alpha$ are cell-autonomously required for the generation of LGs in suprabasal keratinocytes

Three lines of evidence strongly support the conclusion that heterodimers between $\operatorname{PPAR} \beta(\delta)$ and a transcriptionally active RXR $\alpha$ cell-autonomously activate the ex- pression of target genes that are required for LG biogenesis in suprabasal keratinocytes (Fig. 7A). Firstly, ablation of $\operatorname{PPAR} \beta(\delta)$ in suprabasal keratinocytes $\left[\operatorname{PPAR} \beta(\delta)^{\text {sb-/- }}\right.$ mutants] results in LG and related defects very similar to those generated by RXR $\alpha$ ablation. Secondly, either topical treatment with a pan-RXR AF-2 antagonist (BR1211) or impairment of the AF-2 of RXR $\alpha$ (and RXR $\beta$ ) by deletion of the AF-2 core (helix 12) in epidermal keratinocytes (RXR $\alpha \beta^{\text {ep }^{\text {at2o }}}$ mice), which both should not relieve the repression exerted by RAR $\gamma / \mathrm{RXR}$ heterodimers in which RAR $\gamma$ is unliganded (Zhang et al. 1999), also result in LG defects. Thirdly and importantly, a topical application of the PPAR $\beta(\delta)$ agonist L165041 can rescue LG and related defects in $\mathrm{RXR} \alpha \beta^{\mathrm{ep}^{\mathrm{a} 2 \mathrm{ta}}}$ mice, which supports the conclusion that $\operatorname{PPAR} \beta(\delta)$ and $\operatorname{RXR} \alpha$ synergistically contribute to LG biogenesis. In this respect, it is worth stressing that our data additionally indicate that deleting helix 12 of RXR $\alpha$ impairs neither the heterodimerization with $\operatorname{PPAR} \beta(\delta)$ in vitro nor the ligand-dependent activity of the $\operatorname{PPAR} \beta(\delta)$ partner in HepG2 cells. We conclude that it is most likely that the effect of the RXR $\alpha^{a f 2 o}$ mutation is to abrogate the RXR $\alpha$ dependent transcriptional activity, without silencing that of $\operatorname{PPAR} \beta(\delta)$ within the heterodimers. This conclusion is in keeping with our earlier in vivo observations showing that embryos expressing both RXR $\alpha \Delta$ AF- 2 and RXR $\beta \Delta$ AF-2 survive until gestation day 14.5 (Mark et al. 2006), while null mutants for RXR $\alpha$ and RXR $\beta$ (Wendling et al. 1999), PPAR $\beta(\delta)$ (Barak et al. 2002), or PPAR $\gamma$ (Barak et al. 1999) all die at embryonic day 9.5 from highly similar, if not identical, placental defects characterized by the absence of formation of the labyrinthine zone of the chorioallantoic placenta. Therefore, $\operatorname{PPAR} \beta(\delta) / \mathrm{RXR} \Delta \mathrm{AF}-2$ and PPAR $\gamma / \mathrm{RXR} \Delta \mathrm{AF}-2$ heterodimers allow the early step of placentation to take place normally, clearly indicating that AF-2 deletions are not converting RXRs into potent transcriptional repressors that silence their PPAR partners.

That inhibition of cholesterol synthesis by lovastatin induces LG defects (Menon et al. 1992) prompted us to examine whether expression of genes involved in this metabolic pathway could be a target for $\operatorname{PPAR} \beta(\delta) / \mathrm{RXR}$ heterodimers. Hmgcs2, encoding the HMG-CoA synthase 2, is likely to be one of these target genes, as both its expression and cholesterol levels are reduced in the epidermis of $\operatorname{PPAR} \beta(\delta)^{\mathrm{ep}-/(\mathrm{c})}$ and $\operatorname{RXR} \alpha \beta^{\mathrm{ep}-/-(\mathrm{c})}$ newborns, while topical administration of cholesterol cures the LG and related defects displayed by $\operatorname{PPAR} \beta(\delta)^{\mathrm{ep}-/-(\mathrm{c})}$ adults. In addition, Hmgcs2 expression is increased in wild-type adult epidermis topically treated with either the PPAR $\beta(\delta)$-selective agonist L165041 or the pan-RXR agonist BMS649, whereas it is decreased by the pan-RXR antagonist BR1211. These observations, the presence of functional PPAR response element in the Hmgcs2 gene (Rodriguez et al. 1994), the decrease of its expression in the skin of mutant mice lacking RXR AF-2 in their keratinocytes (RXR $\alpha \beta^{\text {ep }}{ }^{\text {at2o }}$ mice), and the enhancement of its expression by the PPAR $\beta(\delta)$ agonist L165041 in these mice, all strongly support, at the molecular level, the conclusion that PPAR $\beta(\delta) / \mathrm{RXR}$ heterodimers, in which 
$\mathrm{RXR} \alpha$ is transcriptionally active, are instrumental to LG biogenesis.

$A$ retinoic acid cannot be the physiological $R X R \alpha$-activating ligand in mouse epidermal suprabasal keratinocytes

Two observations strongly support the conclusion that, within activating PPAR $\beta(\delta) / R X R$ heterodimers, the transcriptionally active $\mathrm{RXR} \alpha$ most probably binds an agonistic ligand, as both (1) deletion of the AF-2 core (helix 12) and (2) topical treatment with an RXR antagonist (BR1211), whose effect can be competed out by a bona fide RXR agonist (BMS649), result in LG and related defects, as well as in decreased expression of the target gene Hmgcs2. Our present study illustrates how, under physiological conditions in the mouse, two signaling pathways, that of $\operatorname{RAR} \gamma$, which is repressing, and that of $\operatorname{PPAR} \beta(\delta)$, which is activating, can be both mediated through heterodimerization with $\operatorname{RXR} \alpha$, under conditions in which an agonistic ligand is bound to $\mathrm{RXR} \alpha$. The solution of this conundrum lies in the so-called subordination mechanism through which the transcriptional activity of an agonist-bound RXR is subordinated, within an RAR/RXR heterodimer, to the binding of an agonistic ligand to its RAR partner. To prevent an agonist-bound $\operatorname{RXR} \alpha$ to transactivate on its own within a $\operatorname{RAR} \gamma / \operatorname{RXR} \alpha$ heterodimer, a corepressor has to bind RAR $\gamma$ in order to block the transcriptional activity of its $\mathrm{RXR} \alpha$ partner (Germain et al. 2002; Gronemeyer et al. 2004). Thus, there should be very little, if any, $\operatorname{RAR} \gamma$-activating retinoic acids in suprabasal keratinocytes in order to allow the binding of a corepressor to $\operatorname{RAR} \gamma$, and to achieve concomitantly $\mathrm{RAR} \gamma / \mathrm{RXR} \alpha$-mediated repression and $\operatorname{PPAR} \beta(\delta) / \mathrm{RXR} \alpha$-mediated activation of target genes that are instrumental to LG biogenesis (Fig. 7A). Several lines of evidence actually support the lack of active retinoids in epidermis (see above for references). That a retinoid is not present in mouse keratinocytes is further supported by the failure of the pan-RAR antagonist BMS493 or of the pan-RXR antagonist BR1211 to decrease Cyp26a1 and Crabp2 expressions that are otherwise inducible by the RA (Supplementary Fig. 1G). In addition, it is known that 9-cis RA, which unlike all-trans RA can bind to RXRs, (1) is nearly as efficient as all-trans RA for binding and activating the RARs, and (2) binds less efficiently to RXRs than to RARs (Allenby et al. 1993). Thus, if 9-cis RA would be the RXR $\alpha$-activating ligand, its presence in suprabasal keratinocytes could also activate RAR $\gamma$ within $\operatorname{RAR} \gamma / \operatorname{RXR} \alpha$ heterodimers, thereby relieving $\mathrm{RAR} \gamma / \mathrm{RXR} \alpha$ repression and inducing LG and related defects (Fig. 7B). We conclude that 9-cis RA is most unlikely to be the $\mathrm{RXR} \alpha$-activating ligand in suprabasal keratinocytes.

An alternative possibility would be that the epidermis is made up of two subtype populations of suprabasal keratinocytes, one in which $\operatorname{PPAR} \beta(\delta) / \mathrm{RXR} \alpha$ heterodimers mediate activation events, and another one in which the RAR $\gamma / \mathrm{RXR} \alpha$-mediated repression events are occurring. This possibility is, however, very unlikely as both the
RAR $\gamma$ and $\operatorname{RXR} \alpha$ proteins (Chapellier et al. 2002a; Metzger et al. 2003), as well as $\operatorname{PPAR} \beta(\delta)$ transcripts (Matsuura et al. 1999), have been uniformly detected in suprabasal keratinocytes. Furthermore, as retinoids are diffusible molecules able to act far away from their site of production (Matt et al. 2005), any RXR $\alpha$-activating retinoid selectively synthesized in keratinocytes containing $\operatorname{PPAR} \beta(\delta) / \mathrm{RXR} \alpha$ would diffuse toward neighboring keratinocytes containing $\operatorname{RAR} \gamma / \operatorname{RXR} \alpha$, unless a retinoid degrading enzyme would be selectively expressed in the latter. That the RA oxidative enzyme Cyp26b1 is uniformly detected in epidermis (Abu-Abed et al. 2002) makes this possibility most unlikely.

Potential RXR agonistic ligands that do not activate RARs include phytol metabolites (Kitareewan et al. 1996), docosahexaenoic acid (de Urquiza et al. 2000), and several unsaturated fatty acids (Goldstein et al. 2003) whose impaired synthesis results in LG defects reminiscent of those described in the present study (Mao-Qiang et al. 1993). As fatty acids activate not only RXRs, but also PPARs, it is tempting to speculate that the same ligand could activate the two partners of $\operatorname{PPAR} \beta(\delta) /$ $\mathrm{RXR} \alpha$ heterodimers. It should, however, be stressed that our present study does not rule out that the transcriptional activity of $\mathrm{RXR} \alpha$ may not be induced by the binding of an agonistic ligand, but through another mechanism; for example, specific phosphorylation events. This possibility cannot be excluded but appears unlikely, because such an event would (1) require the integrity of the RXR ligand-binding domain (LBD) helix 12, (2) have to mimic the binding of an agonist ligand to the LBD of $\mathrm{RXR} \alpha$, and (3) have to be blocked by the binding of a competitive RXR antagonist. In any event, 9-cis RA binding would not be the event triggering the transcriptional activity of $\operatorname{RXR} \alpha$ within the $\operatorname{PPAR} \beta(\delta) / \mathrm{RXR} \alpha$ heterodimer in suprabasal keratinocytes.

In view of the almost ubiquitous presence of RAR $\alpha$ and $\operatorname{RXR} \alpha$ in a variety of cell types, one can wonder whether 9-cis RA could ever be an RXR agonistic ligand in vivo. Investigating, in a variety of tissues/cell types, whether RAR/RXR-mediated repression is concomitant with transactivation mediated by other NR/RXR heterodimers in which RXR is transcriptionally active should tell us where 9-cis RA is unlikely to be an RXR agonistic ligand. Moreover, examining where the expression of genes is reduced both in $\mathrm{RXR}^{\text {af2o }}$ mutants (lacking AF-2) and in vitamin A-deficient (VAD) mice (lacking 9-cis RA) should reveal in which cases 9-cis RA could be an agonistic ligand for RXR in vivo. In this respect, we recently reported that cholesterol efflux from Sertoli cells involves activating LXR $\beta / \mathrm{RXR} \beta$ heterodimers in which RXR $\beta$ AF-2 is transcriptionally active, whereas VAD has no affect on this efflux, which strongly suggests that, in this case also, 9-cis RA is most unlikely to be the RXR $\beta$-activating ligand (Mascrez et al. 2004).

We have proposed elsewhere that low affinity agonist ligands bound to the RXR partners of NR/RXR heterodimers could "sensitize," through synergistic effects, the transcriptional activity of these heterodimers to discrete variations in the concentration of the NR cognate 
ligands (Chambon 2005). In the present case, it is interesting to note that the level of the "sensitizing" RXR ligand is high enough in suprabasal keratinocytes to synergistically reach, with a 3-nmol RAR $\gamma$-selective ligand (BMS961) treatment, the threshold level sufficient to relieve the repression exerted by $\operatorname{RAR} \gamma / \operatorname{RXR} \alpha$ heterodimers, but not to trigger in these cells the paracrine events that induce the proliferation of basal keratinocytes that necessitates an additional cotreatment with the selective RXR ligand BMS649.

\section{Altered $R A R \gamma, P P A R \beta(\delta)$, and $R X R \alpha$-dependent mechanisms may be involved in the etiology of human skin diseases}

Exposure of human skin to UV irradiation results in the formation of "abnormal, vacuolated and lamellar bodydeficient" granular keratinocytes (Holleran et al. 1997). These findings, reminiscent of the phenotype found in our loss-of-function mutants, point to possible alterations of $\operatorname{RAR} \gamma_{-}, \operatorname{PPAR} \beta(\delta)-$, and/or $\operatorname{RXR} \alpha$-dependent functions in LG formation in aging, photo-damaged skin. Along these lines, xerosis senilis is a disorder of keratinization characterized by (1) the presence of vesicles similar in size and shape to LG, but without lamellate internal structure; and (2) the disappearance of the lipid film on top of the cornified layer (Tezuka 1983); two features resembling those displayed by the RAR $\gamma$-, $\operatorname{PPAR} \beta(\delta)-$, and $\operatorname{RXR} \alpha$-null epidermis.

Autosomal recessive congenital ichthyoses (ARCI) are heterogeneous keratinization diseases (Fartasch 1997) that belong either to the erythrodermic scaly type (nonbullous congenital ichthyosiform erythroderma, NCIE) or to the thick lamellar type (lamellar ichthyosis, LI), both of which are characterized by LG and/or abnormalities of multilamellar lipid sheets (Ghadially et al. 1992). Mutations in Alox12b and Aloxe3 genes have been linked to NCIE, while mutations in $\operatorname{Tgm} 1$ have been observed in LI; however, our results rule out altered expression of these genes in RAR $\gamma$ and PPAR $\beta$ loss-of-function mutants (see Supplementary Fig. 3), and none of the "orphan" mutated loci for NCIE or LI colocalized with gene loci encoding RAR $\gamma, \operatorname{PPAR} \beta(\delta)$, and $\operatorname{RXR} \alpha$ (Jobard et al. 2002 and references therein). However, a third type of ARCI of unknown origin, type III congenital ichthyosis, is characterized by the occurrence of LG-derived vesicular complexes accumulating at the apical side of granular keratinocytes and between corneocytes (Arnold et al. 1988; Niemi et al. 1992). This suggests that alteration of $\operatorname{RXR} \alpha-$, RAR $\gamma^{-}$, and/or PPAR $\beta$-dependent mechanisms could be involved in the etiology of some keratinization disorders in humans.

\section{Materials and methods}

\section{Generation of mutants and skin treatments}

Mice bearing floxed alleles and expressing Cre or CreERT ${ }^{2}$ in keratinocytes were genotyped and treated by tamoxifen as described (Metzger et al. 2003). A single dose of retinoids or
L165041 was applied topically on dorsal skin for $5 \mathrm{~d}$, then every second day for $15 \mathrm{~d}$. Skin samples were analyzed $24 \mathrm{~h}$ after the last topical treatment.

Immunohistochemistry, lipid staining, and thin-layer chromatography

Corneodesmosin was detected as described (Montézin et al. 1997). Frozen sections (10 $\mu \mathrm{m}$ thick) of unfixed epidermis were stained with Nile red and examined by fluorescence microscopy $(450 \mathrm{~nm})$. Skin lipids were extracted using the Bligh and Dyer procedure; loaded onto silica plates run in chloroform-methanol $(9: 1, \mathrm{v} / \mathrm{v})$ for $2 \mathrm{~min}$, then in chloroform-diethyl ether-ethyl acetate $(8: 0.4: 1.6, \mathrm{v} / \mathrm{v})$ for $20 \mathrm{~min}$; and revealed by molybdatophosphoric acid staining.

\section{Electron microscopic analyses}

For STEM, the samples were coated with palladium gold and observed with a Philips XL20 electron microscope. For TEM, skin samples were fixed at $4^{\circ} \mathrm{C}$ in Karnovsky's solution, postfixed in ruthenium tetroxide $10.2 \%$ in $100 \mathrm{mM}$ cacodylate buffer), and embedded in Epon 812. Sections (50-70 nm thick) stained with uranyl acetate and lead citrate were examined with a Philips 208 electron microscope. Analysis of acid lipase localization was as described (Menon et al. 1986).

\section{RNA and gene expression analysis}

Quantitative analysis of RNA was carried out by RT coupled to real-time PCR in the presence of SYBR Green I dye (QBIOgen). The specific primers are listed in Supplementary Table 1. EMSA was performed as described (Mascrez et al. 2004) using the mouse Hmgcs2 PPAR response element (Rodriguez et al. 1994). HepG2 cells were transfected with the Hmgcs2 PPRE-tk-Cat construct using JetPEi (Polyplus-Transfection). CAT assays were performed using an Elisa test (Roche), and values were normalized to $\beta$-galactosidase activity.

See the Supplemental Material for details.

\section{Acknowledgments}

We are grateful to Professor E. Grosshans for helpful discussions; to Dr. C. Rochette-Egly and Professor G. Serre for antibodies against RAR $\gamma$ and CDSN, respectively; to Dr. F. Gonzalez for PPAR $\alpha$-null mice; and to Professor W. Walhi and Professor B. Desvergne for the L165041 compound. We thank B. Féret, B. Weber, and M. Teletin, as well as the staff from the animal facility for technical assistance. This work was supported by funds from the Centre National de la Recherche Scientifique (CNRS), Institut National de la Santé et de la Recherche Médicale (INSERM), Collège de France, and Bristol Myers Squibb.

\section{References}

Abu-Abed, S., MacLean, G., Fraulob, V., Chambon, P., Petkovich, M., and Dolle, P. 2002. Differential expression of the retinoic acid-metabolizing enzymes CYP26A1 and CYP26B1 during murine organogenesis. Mech. Dev. 110: 173-177.

Allenby, G., Bocquel, M.T., Saunders, M., Kazmer, S., Speck, J., Rosenberger, M., Lovey, A., Kastner, P., Grippo, J.F., Chambon, P., et al. 1993. Retinoic acid receptors and retinoid X receptors: Interactions with endogenous retinoic acids. Proc. Nat1. Acad. Sci. 90: 30-34.

Andersen, B. and Rosenfeld, M.G. 1995. Intracellular receptors. 
New wrinkles in retinoids. Nature 374: 118-119.

Arnold, M.L., Anton-Lamprecht, I., Melz-Rothfuss, B., and Hartschuh, W. 1988. Ichthyosis congenita type III. Clinical and ultrastructural characteristics and distinction within the heterogeneous ichthyosis congenita group. Arch. Dermatol. Res. 280: 268-278.

Attar, P.S., Wertz, P.W., McArthur, M., Imakado, S., Bickenbach, J.R., and Roop, D.R. 1997. Inhibition of retinoid signaling in transgenic mice alters lipid processing and disrupts epidermal barrier function. Mol. Endocrinol. 11: 792-800.

Barak, Y., Nelson, M.C., Ong, E.S., Jones, Y.Z., Ruiz-Lozano, P., Chien, K.R., Koder, A., and Evans, R.M. 1999. PPAR $\gamma$ is required for placental, cardiac, and adipose tissue development. Mol. Cell 4: 585-595.

Barak, Y., Liao, D., He, W., Ong, E.S., Nelson, M.C., Olefsky, J.M., Boland, R., and Evans, R.M. 2002. Effects of peroxisome proliferator-activated receptor $\delta$ on placentation, adiposity, and colorectal cancer. Proc. Natl. Acad. Sci. 99: 303-308.

Chambon, P. 1996. A decade of molecular biology of retinoic acid receptors. FASEB J. 10: 940-954.

. 2005. The nuclear receptor superfamily: A personal retrospect on the first two decades. Mol. Endocrinol. 19: 14181428.

Chapellier, B., Mark, M., Garnier, J.M., Diérich, A., Chambon, P., and Ghyselinck, N.B. 2002a. A conditional floxed (loxPflanked) allele for the retinoic acid receptor $\gamma(\operatorname{RAR} \gamma)$ gene. Genesis 32: 95-98.

Chapellier, B., Mark, M., Messaddeq, N., Calléja, C., Warot, X., Brocard, J., Gérard, C., Li, M., Metzger, D., Ghyselinck, N.B., et al. 2002b. Physiological and retinoid-induced proliferations of epidermis basal keratinocytes are differently controlled. EMBO J. 21: 3402-3413.

Chen, C.F. and Lohnes, D.L. 2004. Dominant negative RARs elicit epidermal defects through a non-canonical pathway. $J$. Biol. Chem. 280: 3012-3021.

de Urquiza, A.M., Liu, S., Sjoberg, M., Zetterstrom, R.H., Griffiths, W., Sjovall, J., and Perlmann, T. 2000. Docosahexaenoic acid, a ligand for the retinoid $\mathrm{X}$ receptor in mouse brain. Science 290: 2140-2144.

Elias, P.M., Fritsch, P.O., Lampe, M., Williams, M.L., Brown, B.E., Nemanic, M., and Grayson, S. 1981. Retinoid effects on epidermal structure, differentiation, and permeability. Lab. Invest. 44: 531-540.

Fartasch, M. 1997. Epidermal barrier in disorders of the skin. Microsc. Res. Tech. 38: 361-372.

Feng, X., Peng, Z.H., Di, W., Li, X.Y., Rochette-Egly, C., Chambon, P., Voorhees, J.J., and Xiao, J.H. 1997. Suprabasal expression of a dominant-negative RXR $\alpha$ mutant in transgenic mouse epidermis impairs regulation of gene transcription and basal keratinocyte proliferation by RAR-selective retinoids. Genes \& Dev. 11: 59-71.

Fisher, G.J., Talwar, H.S., Xiao, J.H., Datta, S.C., Reddy, A.P., Gaub, M.P., Rochette-Egly, C., Chambon, P., and Voorhees, J.J. 1994. Immunological identification and functional quantitation of retinoic acid and retinoid $\mathrm{X}$ receptor proteins in human skin. J. Biol. Chem. 269: 20629-20635.

Germain, P., Iyer, J., Zechel, C., and Gronemeyer, H. 2002. Coregulator recruitment and the mechanism of retinoic acid receptor synergy. Nature 415: 187-192.

Ghadially, R., Williams, M.L., Hou, S.Y., and Elias, P.M. 1992. Membrane structural abnormalities in the stratum corneum of the autosomal recessive ichthyoses. I. Invest. Dermatol. 99: $755-763$.

Goldstein, J.T., Dobrzyn, A., Clagett-Dame, M., Pike, J.W., and DeLuca, H.F. 2003. Isolation and characterization of unsaturated fatty acids as natural ligands for the retinoid-X recep- tor. Arch. Biochem. Biophys. 420: 185-193.

Gronemeyer, H., Gustafsson, J.A., and Laudet, V. 2004. Principles for modulation of the nuclear receptor superfamily. Nat. Rev. Drug Discov. 3: 950-964.

Holleran, W.M., Uchida, Y., Halkier-Sorensen, L., Haratake, A., Hara, M., Epstein, J.H., and Elias, P.M. 1997. Structural and biochemical basis for the UVB-induced alterations in epidermal barrier function. Photodermatol. Photoimmunol. Photomed. 13: 117-128.

Imakado, S., Bickenbach, J.R., Bundman, D.S., Rothnagel, J.A., Attar, P.S., Wang, X.J., Walczak, V.R., Wisniewski, S., Pote, J., Gordon, J.S., et al. 1995. Targeting expression of a dominant-negative retinoic acid receptor mutant in the epidermis of transgenic mice results in loss of barrier function. Genes \& Dev. 9: 317-329.

Ishida-Yamamoto, A., Simon, M., Kishibe, M., Miyauchi, Y., Takahashi, H., Yoshida, S., O'Brien, T.J., Serre, G., and Iizuka, H. 2004. Epidermal lamellar granules transport different cargoes as distinct aggregates. J. Invest. Dermatol. 122: $1137-1144$

Jobard, F., Lefevre, C., Karaduman, A., Blanchet-Bardon, C., Emre, S., Weissenbach, J., Ozguc, M., Lathrop, M., Prud'homme, J.F., and Fischer, J. 2002. Lipoxygenase-3 (ALOXE3) and 12(R)-lipoxygenase (ALOX12B) are mutated in non-bullous congenital ichthyosiform erythroderma (NCIE) linked to chromosome 17p13.1. Hum. Mol. Genet. 11: 107-113.

Kitareewan, S., Burka, L.T., Tomer, K.B., Parker, C.E., Deterding, L.J., Stevens, R.D., Forman, B.M., Mais, D.E., Heyman, R.A., McMorris, T., et al. 1996. Phytol metabolites are circulating dietary factors that activate the nuclear receptor RXR. Mol. Biol. Cell 7: 1153-1166.

Laudet, V. and Gronemeyer, H. 2002. The nuclear receptor facts book. Academic Press, London.

Lee, S.S., Pineau, T., Drago, J., Lee, E.J., Owens, J.W., Kroetz, D.L., Fernandez-Salguero, P.M., Westphal, H., and Gonzalez, F.J. 1995. Targeted disruption of the $\alpha$ isoform of the peroxisome proliferator-activated receptor gene in mice results in abolishment of the pleiotropic effects of peroxisome proliferators. Mol. Cell. Biol. 15: 3012-3022.

Li, M., Chiba, H., Warot, X., Messaddeq, N., Gérard, C., Chambon, P., and Metzger, D. 2001. RXR $\alpha$ ablation in skin keratinocytes results in alopecia and epidermal alterations. Development 128: 675-688.

Madison, K.C. 2003. Barrier function of the skin: 'La raison d'être' of the epidermis. J. Invest. Dermatol. 121: 231-241.

Mao-Qiang, M., Elias, P.M., and Feingold, K.R. 1993. Fatty acids are required for epidermal permeability barrier function. $J$. Clin. Invest. 92: 791-798.

Mark, M., Ghyselinck, N.B., and Chambon, P. 2006. Function of retinoid nuclear receptors: Lessons from genetic and pharmacological dissections of the retinoic acid signaling pathway during mouse embryogenesis. Annu. Rev. Pharmacol. Toxicol. 46: 451-480.

Mascrez, B., Mark, M., Dierich, A., Ghyselinck, N.B., Kastner, P., and Chambon, P. 1998. The RXR $\alpha$ ligand-dependent activation function 2 (AF-2) is important for mouse development. Development 125: 4691-4707.

Mascrez, B., Ghyselinck, N.B., Watanabe, M., Annicotte, J.S., Chambon, P., Auwerx, J., and Mark, M. 2004. Ligand-dependent contribution of RXR $\beta$ to cholesterol homeostasis in Sertoli cells. EMBO Rep. 5: 285-290.

Matsuura, H., Adachi, H., Smart, R.C., Xu, X., Arata, J., and Jetten, A.M. 1999. Correlation between expression of peroxisome proliferator-activated receptor $\beta$ and squamous differentiation in epidermal and tracheobronchial epithelial cells. 
Mol. Cell. Endocrinol. 147: 85-92.

Matt, N., Dupe, V., Garnier, J.M., Dennefeld, C., Chambon, P., Mark, M., and Ghyselinck, N.B. 2005. Retinoic acid-dependent eye morphogenesis is orchestrated by neural crest cells. Development 132: 4789-4800.

Menon, G.K., Grayson, S., and Elias, P.M. 1986. Cytochemical and biochemical localization of lipase and sphyngomyelinase activity in mammalian epidermis. J. Invest. Dermatol. 86: $591-597$.

Menon, G.K., Feingold, K.R., Mao-Qiang, M., Schaude, M., and Elias, P.M. 1992. Structural basis for the barrier abnormality following inhibition of HMG CoA reductase in murine epidermis. J. Invest. Dermatol. 98: 209-219.

Metzger, D., Indra, A.K., Li, M., Chapellier, B., Calleja, C., Ghyselinck, N.B., and Chambon, P. 2003. Targeted conditional somatic mutagenesis in the mouse: Temporally-controlled knock out of retinoid receptors in epidermal keratinocytes. Methods Enzymol. 364: 379-408.

Montézin, M., Simon, M., Guerrin, M., and Serre, G. 1997. Corneodesmosin, a corneodesmosome-specific basic protein, is expressed in the cornified epithelia of the pig, guinea pig, rat and mouse. Exp. Cell Res. 231: 132-140.

Niemi, K.M., Kanerva, L., Wahlgren, C.F., and Ignatius, J. 1992. Clinical, light and electron microscopic features of recessive ichthyosis congenita type III. Arch. Dermatol. 284: 259-265.

Ohta, K., Iijima, T., Kawachi, E., Kagechika, H., and Endo, Y. 2004. Novel retinoid X receptor (RXR) antagonists having a dicarba-closo-dodecaborane as a hydrophobic moiety. Bioorg. Med. Chem. Lett. 14: 5913-5918.

Perissi, V. and Rosenfeld, M.G. 2005. Controlling nuclear receptors: The circular logic of cofactor cycles. Nat. Rev. Mol. Cell Biol. 6: 542-554.

Randolph, R.K. and Siegenthaler, G. 1999. Vitamin A homeostasis in human epidermis: Native retinoid composition and metabolism. In Retinoids. The biochemical and molecular basis of vitamin $A$ and retinoid action (eds. H. Nau and W.S. Blaner), pp. 491-520. Springer, New York.

Rodriguez, J.C., Gil-Gomez, G., Hegardt, F.G., and Haro, D. 1994. Peroxisome proliferator-activated receptor mediates induction of the mitochondrial 3-hydroxy-3-methylglutarylCoA synthase gene by fatty acids. J. Biol. Chem. 269: 1876718772.

Saitou, M., Sugai, S., Tanaka, T., Shimouchi, K., Fuchs, E., Narumiya, S., and Kakizuka, A. 1995. Inhibition of skin development by targeted expression of a dominant negative retinoic acid receptor. Nature 374: 159-162.

Saurat, J.H., Sorg, O., and Didierjean, L. 1999. New concepts for delivery of topical retinoid activity to human skin. In Retinoids. The biochemical and molecular basis of vitamin $A$ and retinoid action (eds. $\mathrm{H}$. Nau and W.S. Blaner), pp. 521538. Springer, New York.

Tezuka, T. 1983. Electron-microscopic changes in xerosis senile epidermis. Its abnormal membrane-coating granule formation. Dermatologica 166: 57-61.

Wendling, O., Chambon, P., and Mark, M. 1999. Retinoid X receptors are essential for early mouse development and placentogenesis. Proc. Natl. Acad. Sci. 96: 547-551.

Xiao, J.H., Feng, X., Di, W., Peng, Z.H., Li, L.A., Chambon, P., and Voorhees, J.J. 1999. Identification of heparin-binding EGF-like growth factor as a target in intercellular regulation of epidermal basal cell growth by suprabasal retinoic acid receptors. EMBO I. 18: 1539-1548.

Yoshida, M., Kijima, M., Akita, M., and Beppu, T. 1990. Potent and specific inhibition of mammalian histone deacetylase both in vivo and in vitro by trichostatin A. J. Biol. Chem. 265: 17174-17179.
Zhang, J., Hu, X., and Lazar, M.A. 1999. A novel role for helix 12 of retinoid X receptor in regulating repression. Mol. Cell. Biol. 19: 6448-6457. 


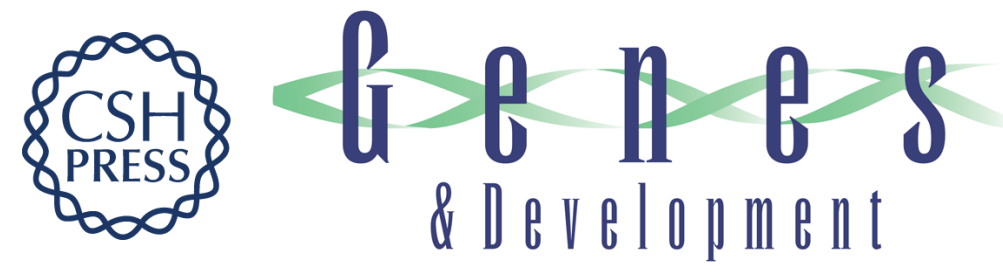

\section{Genetic and pharmacological evidence that a retinoic acid cannot be the RXR-activating ligand in mouse epidermis keratinocytes}

Cécile Calléja, Nadia Messaddeq, Benoit Chapellier, et al.

Genes Dev. 2006, 20:

Access the most recent version at doi:10.1101/gad.368706

Supplemental http://genesdev.cshlp.org/content/suppl/2006/05/16/20.11.1525.DC1
Material

References This article cites 49 articles, 17 of which can be accessed free at:

http://genesdev.cshlp.org/content/20/11/1525.full.html\#ref-list-1

License

Email Alerting Receive free email alerts when new articles cite this article - sign up in the box at the top

Service

right corner of the article or click here.

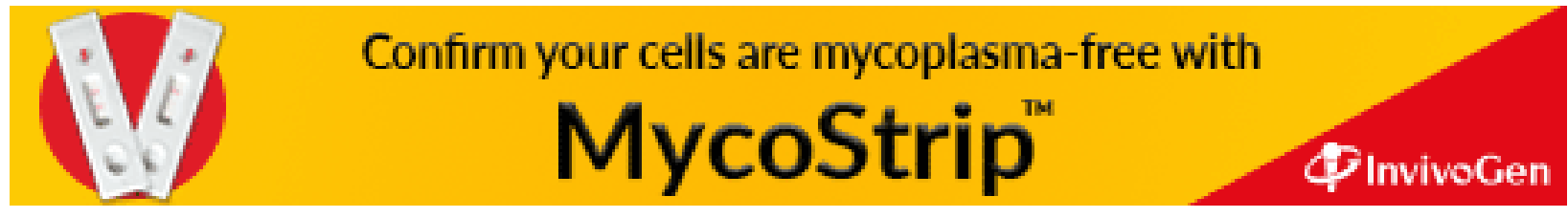

